\title{
A taxonomic review of the genus Astrocladus (Echinodermata, Ophiuroidea, Euryalida, Gorgonocephalidae) from Japanese coastal waters
}

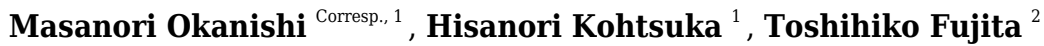 \\ ${ }^{1}$ Misaki Marine Biological Station, Graduate School of Science, The University of Tokyo, Miura, Kanagawa, Japan \\ 2 Department of Zoology, National Museum of Nature and Science, Tsukuba, Tsukuba, Ibaraki, Japan \\ Corresponding Author: Masanori Okanishi \\ Email address: mokanishi@tezuru-mozuru.com
}

Japanese species of the genus Astrocladus (Echinodermata, Ophiuroidea, Euryalida, Gorgonocephalidae) are reviewed. Astrocladus coniferus recently has two junior synonyms, A. dofleini Döderlein and $A$. pardalis Döderlein, however, status of these species has long been questioned. in recent years and no molecular phylogenetic analyses have been performed. Observations of the lectotype of $A$. coniferus, as well as the lectotype and four paralectotypes of $A$. dofleini and the holotype of $A$. pardalis have revealed that $A$. coniferus and $A$. pardalis are conspecific and morphologically distinguishable from $A$. dofleini. Astrocladus coniferus and $A$. dofleini are supported as distinct species by our molecular data. Additionally, we re-describe $A$. exiguus and $A$. annulatus, based on recently collected specimens and the holotype. We conclude that four species, $A$. annulatus, $A$. coniferus, $A$. dofleini, and $A$. exiguus are present in Japanese waters. 


\title{
A taxonomic review of the genus Astrocladus (Echinodermata, Ophiuroidea, Euryalida,
}

\section{Gorgonocephalidae) from Japanese coastal waters}

\author{
Masanori Okanishi ${ }^{1}$, Hisanori Kohtsuka ${ }^{1}$, Toshihiko Fujita ${ }^{2}$
}

${ }^{1}$ Misaki Marine Biological Station, Graduate School of Science, The University of Tokyo, Miura, Kanagawa, Japan

${ }^{2}$ Department of Zoology, National Museum of Nature and Science, Tsukuba, Ibaraki, Japan

Corresponding author:

Masanori Okanishi ${ }^{1}$

1024 Koajiro, Misaki, Miura, Kanagawa 238-0225, Japan

E-mail address: mokanishi@,tezuru-mozuru.com

\section{Abstract}

Japanese species of the genus Astrocladus (Echinodermata, Ophiuroidea, Euryalida, Gorgonocephalidae) are reviewed. Astrocladus coniferus recently has two junior synonyms, $A$. dofleini Döderlein and $A$. pardalis Döderlein, however, status of these species has long been questioned. in recent years and no molecular phylogenetic analyses have been performed.

Observations of the lectotype of A. coniferus, as well as the lectotype and four paralectotypes of A. dofleini and the holotype of $A$. pardalis have revealed that $A$. coniferus and A. pardalis are conspecific and morphologically distinguishable from A. dofleini. Astrocladus coniferus and A. dofleini are supported as distinct species by our molecular data. Additionally, we re-describe A. exiguus and A. annulatus, based on recently collected specimens and the holotype. We conclude that four species, A. annulatus, A. coniferus, A. dofleini, and A. exiguus are present in Japanese waters.

\section{Running title: A taxonomic review of Japanese Astrocladus}

\section{Introduction}

The gorgonocephalid ophiuroids of the genus Astrocladus Verrill, 1899 (Ophiuroidea: Euryalida) are characterized by having cone-shaped external ossicles on the disc; a madreporite present on inner edge of interradial lateral disc; no calcareous plates on the lateral disc margin; and no arm spines before first branch in adults (Fell, 1960; Baker, 1980). The genus is distributed from the Indo-Pacific to southern Africa (e.g. A. M. Clark \& Courtman-Stock, 1976; Baker, 1980; McKnight, 2000). It was 
established by Verrill (1899) for Euryale verrucosum Lamarck, 1816 (= Astrocladus exiguus (Lamarck, 1816)) and it currently comprises 10 species: Astrocladus africanus Mortensen, 1933 from southern Africa; A. annulatus Matsumoto, 1915 from Japan; A. coniferus (Döderlein, 1902) from Japan; A. euryale (Retzius, 1783) from southern Africa; A. exiguus (Lamarck, 1816) from the Indo-West Pacific; $A$. goodingi Baker, Okanishi \& Pawson, 2018 from the western Indian Ocean; A. hirtus Mortensen, 1933 from South Africa; A. ludwigi (Döderlein, 1896) from Indo-Western Pacific; A. socotrana Baker, Okanishi \& Pawson, 2018 from northern Indian Ocean, and A. tonganus Döderlein, 1911 from Tonga and New Zealand (Retzius, 1783; Lamarck, 1816; Lyman 1875, 1882; Koehler, 1897, 1905, 1907, 1930; H. L. Clark, 1911, 1915, 1923; Döderlein, 1896, 1911, 1927; Matsumoto, 1915; Mortensen, 1933; Murakami, 1944a, 1944b; Djakonov, 1954; A. M. Clark, 1951, 1974; A. M. Clark \& Rowe, 1971; A. M. Clark \& Courtman-Stock, 1976; Irimura, 1969, 1981, 1982; Cherbonnier \& Guille, 1978; Baker, 1980; McKnight, 1989; 2000; Liao \& A. M. Clark, 1995; Rowe \& Gates, 1995; Irimura \& Tachikawa, 2002; Baker et al., 2018). Of these, three species are currently known from Japanese waters: A. annulatus, A. coniferus, and A. exiguus (e.g. Döderlein, 1911; Matsumoto, 1915; Irimura, 1981).

The holotype of Astrocladus annulatus was described, from central Japan (Matsumoto, 1915, 1917) and subsequently recorded again from on a specimen from western Japan (Irimura, 1981); Astrocladus exiguus was recorded from central and western Japan, respectively (H. L. Clark, 1915; Irimura, 1981); and Astrocladus coniferushas been recorded from Japanese waters except Hokkaido Island (Döderlein, 1902, 1910, 1911; H. L. Clark, 1911; Matsumoto, 1917; Murakami, 1944b; Irimura, 1979, 1981, 1982, 1990; Yi \& Irimura, 1987; Fujita \& Kohtsuka, 2003; Okanishi et al., 2011a; Kohtsuka et al., 2017).

In these three species, the taxonomic status of $A$. coniferus, which is currently synonymized with A. dofleini and A. pardalis, has been controversial. Astrocladus coniferus and A. pardalis were both originally described by Döderlein (1902) in the genus Astrophyton and they were mainly distinguished by presence/absence of large conical tubercles on radial shield and dorsal proximal portion of arms (Döderlein, 1902). Subsequently, Döderlein (1910) moved the two species to Astrocladus Verrill, 1899 and synonymized $A$. pardalis with A coniferus. In the same paper, Döderlein described Astrocladus dofleini, which is distinguished from $A$. coniferus in having numerous granular large tubercles on the dorsal disc. Since then, some taxonomists have considered A. coniferus (with synonymy of A. pardalis) and A. dofleini to be separate taxa (Döderlein, 1910; Saba et al., 1982; Irimura, 1990), others have regarded the three taxa as distinct (sub)species (Matsumoto, 1917; Fedotov, 1926; Irimura, 1982; Shin \& Rho, 1996) or united them as $A$. coniferus without any (sub)specific division (Murakami, 1944a, b; Fujita \& Kohtsuka, 2003). The type specimens of A. coniferus, A. dofleini and A. pardalis have not been formally re-examined since their original descriptions by Döderlein (1902, 1910, 1911),

The other two Japanese species, $A$. annulatus and $A$. exiguus, has been distinguished from $A$. coniferus (and also from A. dofleini and A. pardalis) by the possession of a covering of external ossicles on 
the dorsal body. However, no detailed description, including photographs of the body and/or SEM images of ossicles has been provided for $A$. annulatus and A. exiguus.

All of the previous studies of Astrocladus were based on morphological characters alone. Molecular data for Astrocladus spp. has only been published in four papers (Okanishi et al., 2011b; Okanishi \& Fujita, 2013; O’Hara et al., 2017; Christodoulou et al., 2019).

In this study, to address the taxonomic status of Astrocladus coniferus, we compared the morphology of the type specimens, for A. coniferus, A. pardalis and A. dofleini, and we obtained partial mitochondrial COI genes for 7 specimens which were morphologically consistent with type specimens of those three species. Partial mitochondrial COI of the two specimens of $A$. exiguus were also included in the phylogenetic analysis to estimate species delimitation by measuring genetic distance within Astrocladus. Additionally, we re-describe A. annulatus based on newly collected material, as well as the type specimens, and we re-describe A. exiguus based on newly acquired specimens.

\section{Materials \& Methods}

\section{Specimens examined}

The 7 type specimens examined in this study are deposited in The University Museum, The University of Tokyo, Japan (UMUT), the Zoologische Staatssammlung München, Germany (ZSM), and Museum für Naturkunde der Humboldt-Universität zu Berlin, Germany (ZMB). Other newly collected specimens for molecular analysis are deposited in the National Museum of Nature and Science, Tsukuba, Japan (NSMT) (Table 1).

One lectotype of Astrophyton coniferum (ZSM 453/1), one lectotype (one of four specimens of ZSM 440/1), four paralectotypes (three specimens of ZSM 440/1 and one specimens of ZMB 5923) of Astrocladus dofleini (ZSM 440/1 and), the holotype of Astrocladus pardalis (ZSM 453/2) and the holotype of Astrocladus annulatus (UMUTZ-Echi-Oph-26) are preserved in ethanol, but their fixation methods are unknown.

The specimens for molecular analysis were collected by commercial fishing lines of at Minabe Port, Wakayama Prefecture (2 specimens), by fisherman with small trawl at Mogi, Nagasaki Prefecture (4 specimens), by scuba diving at Hashiraguri, Oki Island, Shimane Prefecture (1 specimen) and by scuba diving near Misaki Marine Biological Station, Kanagawa Prefecture ( 2 specimens). The specimens were fixed and preserved in 70-99\% ethanol. Permission for all of these newly collected nine specimens were approved by Miura fishermen's association (Kanagawa Prefecture) Mogi fishermen's association (Nagasaki Prefecture), Kishu-Hidaka fishermen's association (Wakayama Prefecture), WakayamaMinami fishermen's association (Wakayama Prefecture), and JF Shimane fishermen's association (Shimane Prefecture). 


\section{Morphological observation and terminology}

Ossicles from Astrocladus coniferus (NSMT E-13118), A. dofleini (NSMT E-13124) and $A$. exiguus (NSMT E-13126) were isolated by immersion in domestic bleach (approximately 5\% sodium hypochlorite solution), washed in deionized water, air-dried, and mounted on SEM stubs using doublesided conductive tape. The ossicles were observed and photographed with a Jeol JSM 5200LV SEM at Misaki Marine Biological Station, The University of Tokyo. A part of photographs were focus-stacked using the software CombineZM v. 1.0.0 (https://www.softpedia.com/get/Multimedia/Graphic/GraphicEditors/CombineZM.shtml). The size of external ossicles, represented by the length of the longest axis, it is referred to as "length" in this study.

The morphological terms used to describe euryalid brittle stars follow Thuy and Stöhr, (2011), Stöhr et al. (2012), Okanishi (2016) and Hendler (2018). The granular external ossicle is referred to as a "granule" in this paper. Taxonomic arrangement follows Christodoulou et al. (2019).

\section{DNA extraction, amplification and sequencing}

Genomic DNA was extracted using DNeasy Blood and Tissue extraction kit (Qiagen) according to the manufacturer's protocol. We sequenced mitochondrial COI gene for phylogenetic analysis. The method of DNA extraction and PCR parameters followed Okanishi \& Fujita (2013). A primer set of COI005 (5'-TTAGGTTAAHWAAACCAVYTKCCTTCAAAG-3') and COI008 (5CCDTANGMDATCATDGCRTACATCATTCC-3') (Okanishi and Fujita,2013) was used for PCR of COI. The optimum cycling parameters for those COI primers consisted of an initial denaturation step of $94^{\circ} \mathrm{C} / 2$ min followed by 41 cycles of $94^{\circ} \mathrm{C} / 30 \mathrm{~s}, 48^{\circ} \mathrm{C} / 90 \mathrm{~s}$ and $72^{\circ} \mathrm{C} / 60 \mathrm{~s}$ with final extension step at $72^{\circ} \mathrm{C} / 10$ min was followed by storage at $4^{\circ} \mathrm{C}$. The PCR products were separated from excess primers and oligonucleotides using Exo-SAP-IT (GEHealthcare) by following manufacturer's protocol. All samples were sequenced bidirectionally and sequence products were run on the 3730xI DNA Analyzer of Misaki Marine Biological Station. The accession numbers of the DNA Data Bank of Japan (DDBJ) are shown in Table 1.

\section{Phylogenetic analysis}

We sequenced 2 specimens of Astrocladus coniferus, 5 specimens of Astrocladus dofleini and 2 specimens of $A$. exiguus, but sequence data from a single specimens of $A$. dofleini (referred as $A$. coniferus in Okanishi \& Fujita, [2013, 2018]) and A. exiguus obtained by Okanishi \& Fujita $(2013,2018)$ were also used. A. exiguus was added to the analysis to compare genetic distances and to determine the taxonomic rank of each phylogenetic group within Astrocladus. For outgroups, we selected 6 species of the subfamily Gorgonocephalinae with the shortest genetic distance from Astrocladus to avoid long branch attraction (Bergsten, 2005; Okanishi \& Fujita, 2018). These species were also used in a previous molecular phylogeny (Okanishi \& Fujita, 2013, 2018). 
145

146

147

All sequences were aligned using the Clustal W algorithm in MEGA X (Thompson et al., 1994; Kumar et al. 2018). All missing sequences were scored as gaps. Overall average of substitution rate was computed using MEGA X according to the Kimura 2-parameter model (Kimura, 1980) to compare the evolutionary rate of each gene. The K2P, HKY and TN93 with gamma distributions were selected as bestfit models of the first, second and third codons, respectively (Kimura, 1980; Hasegawa et al., 1985; Tamura \& Nei, 1993), by using the "Find best fit models" option of MEGA X. Seaview ver. 4.3.0 (Gouy et al., 2010) were used in preparing the data matrices in PHYLIP format.

Figtree v1.4.3 (http://tree.bio.ed.ac.uk/software/figtree/) was used in exploring tree files, in preparing NEWICK format and exploring alternative tree topologies. The phylogenetic tree was constructed with RAxML ver. 8.1.20 (Stamatakis, 2014) for maximum likelihood analysis (ML) to obtain bootstrap support values and with MrBayes v. 3.1.2 (Ronquist \& Huelsenbeck, 2003) to obtain Bayesian posterior probabilities (BPP). The Markov-Chain Monte-Carlo (MCMC) process was run with four chains for 3,000,000 generations, with trees being sampled every 100 generations. The first 7,500 trees were discarded as burn-in. Data sets were partitioned by each codon for the maximum likelihood analysis to allow for separate optimization per-site substitution rates. The best-supported likelihood tree was found by performing 1000 replications.

$\mathrm{K} 2 \mathrm{P}$ genetic distances were computed within each clade and between clades using MEGA $\mathrm{X}$ to compare the evolutionary rate of COI gene.

\section{Systematics \\ Order Euryalida Gray, 1840 \\ Family Gorgonocephalidae Ljungman, 1867 \\ Genus Astrocladus Verrill, 1899 \\ Type species: Euryale verrucosum Lamarck, 1816 (=Astrocladus exiguus (Lamarck, 1816))}

\section{Diagnosis}

Arms five, branching. Number of arm segments less than six before first branch. No rows of calcareous plates on edge of disc margin. One madreporite situated on oralmost portion of interradial lateral disc. Arm spines present before the first branch. Hooklets on dorsal arms with one secondary tooth. Disc covered by variously shaped external ossicles and/or large tubercles (Döderlein, 1927; Baker, 1980; McKnight, 2000).

\section{Remarks}

Our molecular and morphological results have confirmed that Astrocladus pardalis (Döderlein, 
181 1902) is a junior synonym of $A$. coniferus (Döderlein, 1902) which can be separated from $A$. dofleini 182 (Döderlein, 1910). Therefore, 11 species are now known in this genus (see list of "Included species"

183

184

185

186

187

188

189

190

191

192

193

194

195

196

197

198

199

200

201

202

203

204

205

206

207

208

209

210

211

212

213

214

215

216

\section{Included species}

A. africanus Mortensen, 1933; A. annulatus (Matsumoto, 1912); A. coniferus (Döderlein, 1902); A. dofleini Döderlein, 1910; A. euryale (Retzius, 1783); A. exiguus (Lamarck, 1816); A. goodingi Baker, Okanishi \& Pawson, 2018; A. hirtus, Mortensen, 1933; A. ludwigi (Döderlein, 1896); A. socotrana Baker, Okanishi \& Pawson, 2018; A. tonganus Döderlein, 1911.

\section{Astrocladus coniferus (Döderlein, 1902)}

(Figs. 1-7)

Astrophyton coniferum Döderlein, 1902, 325, 326; Jangoux 1987, 306.

Astrocladus coniferus.-Döderlein, 1911, 46-49, taf. 2, fig. 7, 7a; taf. 4, figs. 1-3a; taf. 7, 5, 6a, 16; 1912; Clark, H.L., 1915, 186; Fedotov, 1926, 473-477; Murakami, 1944a, 247-248; 1944b, 262; Djakonov, 1949, 50; 1954, 20; Irimura, 1968, 32; 1969, 39; 1981, 18-19; Liao \& Clark A.M., 1995, 170; Ishida et al., 2001, 8; Fujita et al., 2004, 192, 193; Okanishi et al., 2011, 378, 379, fig. 6G-J.

Astrocladus coniferus coniferus.-Irimura, 1982, 9-11, fig. 5, pl. 1(3); Rho \& Shin, 1987, 209, 211; Shin, 1992, 118, 121; Shin \& Rho, 1996, 389; Ishida et al., 2001, 8.

Astrocladus coniferus pardalis.-Saba et al., 1982, 27. pl. 14 (2, 3); Shin \& Rho, 1996, 390; Ishida et al., 2001, 8 .

Astrophyton cornutum.-Clark, H.L., 1911: 293.

Astrophyton pardalis Döderlein, 1902, 323; Clark, H.L., 1911, 293-294; Jangoux et al., 1987, 308.

Astrocladus coniferus var. pardalis.-Matsumoto, 1917, 77; Fedotov, 1926, 473-477; Djakonov, 1954, 20. (Non) Astrocladus coniferus coniferus.-Saba et al., 1982, 26-27, pl. 14(1) (=Astrocladus dofleini)

(Non) Astrocladus coniferus.-Matsumoto, 1917, 77-79, fig. 23c; Irimura, 1990, 75, an unamed pl.; Fujita \& Kohestuka, 2003, 27, 28, pl. 1B (=Astrocladus dofleini)

(Non) Astrocladus coniferus var. pardalis.-Irimura, 1982, 12-13, fig. 7, pl. 4(4) (=Astrocladus dofleini)

\section{Notes on lectotype}

In the original description (Döderlein, 1902), Astrophyton coniferum (=Astrocladus coniferus) was thought to have been described based on two specimens which are listed in a table (Döderlein, 1902, P326). They were collected in Kagoshima Bay at, ca. $30 \mathrm{~m}$ depth and subsequently, one of them was figured by the same author in 1911 as "Typus" of Astrocladus coniferus (Döderlein, 1911, Taf 4, 2-2a). This is in accordance with $\S 75.4$ of the International Code of Zoological Nomenclature, and it can be 
217

218

219

220

221

222

223

224

225

226

227

228

229

230

231

232

233

234

235

236

237

238

239

240

241

242

243

244

245

246

247

248

249

250

251

252

regarded as the lectotype. The morphological traits of ZSM 453/1 concur with this figured specimen. Therefore, ZSM 453/1 is the lectotype.

\section{Type material examined}

ZSM 453/1, the lectotype of Astrophyton coniferum (Döderlein, 1902) (Astrocladus coniferus), Kagoshima Bay, ca 30 m, Japan, 1880 August (Fig. 2A, B). ZSM 453/2, the holotype of Astrophyton pardalis (Döderlein, 1902), collected by Karl Haberer, Sagami Bay, Japan, date unknown (Fig. 4B). In the original description (Döderlein, 1902), Astrophyton pardalis was implied to be described based on the single specimen, listed in a table (Döderlein, 1902, P326). Therefore, this specimen (ZSM 453/2) is the holotype by monotypy (ICZN Article 73.1.2.; see also Jangoux, 1987)

\section{Other material examined}

NSMT E-13118, Sagami Bay, Hama Moroiso, Kanagawa, Japan, 0.5-1.0 m, 12 March 2018, collected by Hisnaori Kohtsuka, scuba. NSMT E-13119, Hashiraguri, Oki Island, Dohgo, Shimane, Japan, 20 m, 15 July 2010, collected by Hisanori Kohtsuka, scuba.

\section{External morphology of the lectotype (ZSM 453/1)}

Disc. Disc five-lobed with notched interradial edges, $60 \mathrm{~mm}$ in diameter (Fig. 2C). Dorsal disc wholly covered by external ossicles in contact with each other. Radial shields completely covered by granules and conical external ossicles, approximately $110-450 \mu \mathrm{m}$ in length; other areas covered by smaller granules, approximately $100 \mu \mathrm{m}$ in length (Fig. 2F). Radial shields tumid, bar-like, approximately $50 \mathrm{~mm}$ in length, width gradually decreasing from $10 \mathrm{~mm}$ at disc periphery to $2.5 \mathrm{~mm}$ almost at disc center (Fig. 2E). One large conical tubercle on peripheral edge of each radial shield, 2.5-3.4 mm in length (Fig. 2E).

Ventral surface of disc completely covered by skin and polygonal plate-like external ossicles, fully in contact, approximately $600 \mu \mathrm{m}$ in length (Fig. 2G). Oral shields, adoral shields, oral plates and ventral arm plates completely concealed by ossicles (Fig. 2G). Teeth uniformly spiniform, situated on top of dental plates (Fig. 2G). Teeth arranged in a cluster covering ventral-most part of dental plate approximately 10 in number (Fig. 2G), and in a vertical line, on dorsal part of dental plates, 3 or 4 in number. Spiniform oral papillae situated in 1 or 2 transverse rows on ventral edge of each oral plate, 4 to 5 in number (Fig. 2G). Size of teeth varying in position on jaw, approximately 400-1000 $\mu \mathrm{m}$ in length and oral papillae approximately $400 \mu \mathrm{m}$ in length (Fig. 2G).

Interradial surface of lateral disc covered by granules fully in contact, approximately $100 \mu \mathrm{m}$ in length (Fig. 2G, H). Two genital slits (5 mm long and 1-3 mm wide) in each interradius (Fig. 2G). One large, elliptical madreporite situated on ventral interradius, approximately $5.5 \mathrm{~mm}$ in width and $3.75 \mathrm{~mm}$ in length (Fig. 2H).

Peer] reviewing PDF | (2020:05:49200:1:2:CHECK 31 Jul 2020) 
Arms. Arms branching. On proximal portion before first branch, arm $8.5 \mathrm{~mm}$ wide with arched dorsal surface and flattened ventral surface (Fig. 3A). Between first branch and second branch, arm width abruptly decreases to $5.8 \mathrm{~mm}$. Subsequently, arms tapering gradually toward arm tip (Fig. 3).

On dorsal and lateral surface, each arm segment covered by single annular row of large hookletbearing plates (Fig. 3A, B). Before second branch, each plate separated by granules. Plates fully in contact from third branch and subsequent distal segments (Fig. 3B). With exception of hooklet-bearing plates dorsal and lateral surface of arm completely covered by granules, fully in contact, approximately 200-400 $\mu \mathrm{m}$ in length (Fig. 3A). Before first branch, ventral surface covered by polygonal plate-like external ossicles, similar to those on ventral disc, approximately $100 \mu \mathrm{m}$ in length (Fig. 3C). After first branch, ossicles become into round granules, slightly in contact, and decreasing in size gradually toward arm tip (Fig. 3D). With exception of the articulations with arm spines and/or hooklets, lateral arm plates and ventral arm plates completely concealed by external ossicles on entire arm (Fig. 3C, D). Tentacle pore with single arm spine before first branch; 2 or 3 spines after first branch; up to 4 spines on subsequent pores (Fig. 3C, D). Number of arm spines decrease gradually to 2 towards arm tip. Arm spines approximately one-seventh to one-eighth (ca. 12-13\%) of length of the corresponding arm segment on proximal portion of arm, and one-thirds to one-fourth length of the corresponding arm segment on middle to distal region of arm (Fig. 3C, D).

Color. Uniformly dull brown in ethanol preserved specimen (Fig. 2C, D).

\section{Description of other materials}

External morphology of ZSM 453/2: Disc approximately $30 \mathrm{~mm}$ in diameter (Fig. 4A, C). The external ossicles on radial shield conical with acute tip (Fig. 4D). No large tubercle on periphery of radial shields (Fig. 4C), tubercle present in lectotype of Astrophyton coniferum (ZSM 453/1). Teeth and oral papillae not spiniform, but granular (Fig. 4E).

Living color of NSMT E-13118: Dorsal disc (diameter $=30 \mathrm{~mm}$ ) vivid orange with yellow patches, arms with yellow transverse bands on dorsal side (Fig. 4G). Ventral side of arms and disc uniformly creamy white, with orange arm tip (Fig. 4H).

Ossicle morphology of NSMT E-13118: All arm hooklets with single inner tooth and reticular structures (Fig. 5A-C). Inner tooth on distal portion of arm smaller and more rudimentary than those from proximal to middle portion of arm. Hooklet-bearing plates with 9 or 10 tubercle-shaped articulations for hooklets in proximal portion of arm; articulations forming 2 parallel rows (Fig. 5D). On proximal to middle portion of arm, lateral arm plates longer than high, curved to distal side (Figs. 5E, F, I, J). On proximal portion of arm, simple muscle openings besides border structures on distal edge (Fig. 5F), and on middle portion of arm, nerve openings on internal side of the muscle openings (Fig. 5I). One perforation present on internal side (Fig. 5J). On distal portion of arms, plate square, at least one nerve opening of articulation for arm spine beside border structure and one articulation for hooklet on distal side 
289 (Fig. 6A). No perforations recognizable on internal side (Fig. 6B). On proximal and middle portion of 290 arm, arm spines ovoid, with three or four terminal projections, approximately one-third to one-fourth 291 length of the height of arm spine (Fig. 5G, H, K, L). In distal portion, arm spines transformed into hooks 292 with one inner secondary tooth (Fig. 6C). Hook-shaped arm spines distinguished from hooklets by lack of 293 reticular structure (Figs. 5A-C; 6C).

294 All vertebrae with hourglass-shaped streptospondylous articulations (Figs. 6D, F, G; 7C, D). In middle portion of arm, surfaces of lateral furrows smooth, with tubercle shaped ornamentations on dorsal side (Fig. 7B). In distal portion of arm, depressions for tube feet openings in distal part of ventral-lateral side of vertebrae but these are unrecognizable on proximal to middle portion of arm (Figs. 7E). A pair of channels for passage of lateral nerves opening inside ventral furrows (Figs. 6E; 7A, E). In middle portion of arm channels for passage of lateral canals also opening on distal side of canals of lateral nerves (Fig. 7A). Channels for lateral nerve obscured in distal portion of arm (Fig. 7E).

\section{Distribution}

303

304

Many records of Astrocladus coniferus have been confused with those of $A$. dofleini. Therefore, only those that can be identified as $A$. coniferus by their figures and/or photographs are listed here. JAPAN: Kagoshima Bay, southwestern Japan, ca. 20 m (Döderlein, 1902, 1911; type locality, Fig. 1), Sagami Bay, Kanagawa, central-eastern Japan, 1.5-130m (Döderlein, 1902, 1911; Irimura, 1982; This study, Fig. 1), Off Hachijojima Island and Ogasawara Islands, south-eastern Japan, 120-500 m (Okanishi et al., 2011a). Off Kii Nagashima, Mie, central Japan, depth unknown (Saba et al., 1982); Hashiraguri, Oki Island, Shimane, western Japan, ca. 20 m (This study).

\section{Discussion}

In this study, we propose that $A$. pardalis is a junior subjective synonym of $A$. coniferus (see Remarks of $A$. dofleini for the details). A. coniferus can be distinguished from other congeners in having; granules and conical external ossicles on dorsal disc, and 0 or 1 conical large tubercles on the peripheral edge of each radial shield (Table 2).

Astrocladus dofleini Doderlein, 1910

(Figs. 8-12)

Astrocladus dofleini Döderlein, 1910, 256; 1911, 41-46, 106, fig. 9, taf. 2, fig. 6, taf. 3 figs. 1-4, taf. 4, figs. 4, 5, taf. 7, 15, 15b; 1927, 35, 94, taf. 3, fig. 2.; Guille, 1981, 416, 417; Jangoux et al., 1987, 306. Astrocladus coniferus dofleini.-Rho and Shin, 1987, 209, 211; Yi \& Irimura, 1987, 122, 123, fig. 2; Shin, 1992, 253; 1995, 117, 121; Shin \& Rho, 1996, 391; Ishida et al., 2001, 8. 
324

325

326

327

328

329

330

331

332

333

334

335

336

337

338

339

340

341

342

343

344

345

346

347

348

349

350

351

352

353

354

355

356

357

358

359

Astrocladus coniferus var. dofleini.-Matsumoto, 1917, 77-79, fig. 23; Fedotov, 1926, 473-477;

Djakonov, 1949, 50; 1954, 20; Irimura, 1968, 32; 1979, 2; 1981, 19; 1982: 11, 12, fig. 6, pl. 4, figs. 5, 6.

Astrocladus coniferus.-Matsumoto, 1917, 77-79, fig. 23; Irimura, 1990, 75, pl; Fujita \& Kohtsuka, 2003, 27, pl. 1B; Kohtsuka et al., 2017, 229-233, figs. 2-5 (Non Astrocladus coniferus).

Astrocladus coniferus coniferus.-Saba et al., 1982, 26-27, pl. 14(1) (Non Astrocladus coniferus)

Astrocladus coniferus var. pardalis.- Irimura, 1982: 12, 13, text-fig. 7, pl. 4, fig. 4 (Non Astrocladus pardalis).

Astrocladus verrucosus.-Verrill, 1899, 369 (Non Astrocladus verrucosus (Lamarck, 1816)).

(Non) Astrocladus dofleini.-Bomford, 1913, 220, 221, pl. 13, fig. 1 (=Astrocladus exiguus).

\section{Notes on lectotype}

In the original description (Döderlein, 1910), this species was based on a specimen in the Peabody Museum of Natural History (Yale University) which was reported as A. verrucosus by Verrill (1899), plus several specimens collected from Japan. Subsequently, one of them was figured by Döderlein (1911), and named the "Typus" of Astrocladus coniferus. In accordance with $\$ 75.4$ of the International Code of Zoological Nomenclature, the author "unambiguously selected a particular syntype to act as the unique name-bearing type of the taxon", namely the lectotype. The morphological traits of one of the 4 specimens of ZSM 440/1 concur with the specimen figured by Döderlein (1911). Therefore, the specimen of ZSM 440/1 is designated as the lectotype, and the other three specimens as paralectotypes.

\section{Type material}

ZSM 440/1, the lectotype and three paralectotypes of Astrocladus dofleini Döderlein, 1902, Okinose, Sagami Bay, ca 600 m, Japan, 1904-1905, collected by Franz Doflein (Fig. 8B). ZMB 5923, a paralectotype of Astrocladus coniferus Döderlein, 1902, Sagami Bay, depth unknown, Japan, collected by Karl Haberer.

\section{Other material examined}

NSMT E-13124, 1 specimen, Sagami Bay, Mouth of Koajiro Bay, Kanagawa, Japan, ca. 15 m, 6 June 2018, collected by Hisanori Kohtsuka, Scuba. NSMT E-13120, NSMT E-13121, NSMT E-13122, NSMT E-13123, 4 specimens, Tachibana Bay, off Mogi, Nagasaki, Japan, ca. 40 m, 7 February 2018, collected by Hatsuyuki Takeshita, Small trawl. NSMT E-5480, 1 specimen, off Minabe, Wakayama, Japan, ca. 80 m, 10 March 2006, collected by Hajime Watabe, gill net. NSMT E-10749, 1 specimen, Kuji Port, Hitachi, Ibaraki, Japan, 36 30.50N, 140.38.40.E, depth unknown, 30 September, 2016, collected by fishery boat Daisan-shouei-Maru, fishing net. 
360

361

362

363

364

365

366

367

368

369

370

371

372

373

374

375

376

377

378

379

380

381

382

383

384

385

386

387

388

389

390

391

392

393

394

395

\section{Description of external morphology of the lectotype (ZSM 440/1)}

Disc. Disc circular with slightly notched interradial edges, $53 \mathrm{~mm}$ in diameter (Fig. 8C). Radial shields tumid (Fig. 8C). Dorsal disc wholly covered by granules in contact each other and domed large tubercles (Fig. 8C). Radial shields covered by granules, approximately $200-330 \mu \mathrm{m}$ in length (Fig. 8C). and large domed tubercles, 20-25 on each radial shield in number, each approximately $2.5-3.4 \mathrm{~mm}$ in length (Fig. 8C). Radial shields bar-like, approximately $25 \mathrm{~mm}$ in length, and the width gradually decreasing from $4.6 \mathrm{~mm}$ at disc periphery to $1.5 \mathrm{~mm}$ almost reaching to disc center (Fig. 8C).

Ventral surface of disc covered by polygonal plate-shaped external ossicles, fully in contact. Oral shields, adoral shields, oral plates and ventral arm plates concealed by ossicles (Fig. 8E). Teeth uniformly small, granule-like, situated on the top of dental plates, forming a cluster, approximately 6 to 8 in number (Fig. 8E). Oral papillae on the ventral edges of oral plates, forming a transverse row on each plate, 1 or 2 in number (Fig. 8E). Interradial surface of lateral disc covered by granules fully in contact, approximately $170 \mu \mathrm{m}$ in length, and domed tubercles, approximately $200-500 \mu \mathrm{m}$ in length (Fig. 8E). Two pore-like genital slits (6.5 mm long, $3 \mathrm{~mm}$ wide) in each interradius (Fig. 8E).

Arms. Arms branching. On proximal portion before first branch, arm $16 \mathrm{~mm}$ wide with an arched dorsal surface and flattened ventral surface (Fig. 8D, E). Between first branch and second branch, arm width abruptly decreasing to $10 \mathrm{~mm}$. Subsequently, arms tapering gradually toward arm tip (Fig. 8F, $\mathrm{H})$.

On dorsal and lateral surface, each arm segment covered by single annular row of hookletbearing plates. Before third branch, each plate separated by granules. The plates fully in contact from fourth branch and subsequent distal segments. With exception of hooklet-bearing plates, dorsal and lateral surface of arm completely covered by granules, fully in contact, approximately $100 \mu \mathrm{m}$ in length. Before the first branch, ventral surface covered by polygonal and plate-shaped external ossicles, similar to those on ventral disc. After the first branch, the ossicles transforming granules, slightly in contact, and decreasing in size gradually toward the distal arm tip. With exception of the articulations with arm spines and/or hooklets, lateral arm plates and ventral arm plates concealed by external ossicles on entire arm (Fig. 8E, G, H). Tentacle pore with single arm spine after the first branch; 1 or 2 spines after second branch; and up to 4 spines for the subsequent pores (Fig. 8G, H). Distally, the number of arm spines decreasing gradually to 2 toward arm tip. Arm spines approximately one-fourth to one-fifth of length (ca. $20-25 \%$ ) of corresponding arm segment on proximal portion of arm, and one-thirds to one-fourth length of corresponding arm segment on middle to distal arm segment (Fig. 8G, H).

Color. Uniformly dull brown with whitish large tubercles in ethanol preserved specimen (Fig. 8).

\section{Description of other materials}

Ossicle morphology of NSMT E-13124: Each hooklet on proximal and middle portion of arm 
with single inner secondary tooth, distal portion of arm with two inner secondary teeth. All hooklets with reticular structures (Figs. 9A, B, D). Hooklet-bearing plates with 6, 8 and 6 tubercle-shaped articulations for hooklets in proximal, middle and distal portion of the arm, respectively; articulations forming 2 parallel rows (Figs. 9C, E; 10B).

On proximal portion of arm, lateral arm plates long, with straight both proximal and distal edges (Fig. 9G, H); edges ellipse-shape in middle (Fig. 9J, K) and distal (Fig. 10B, C) portion of arms. No perforation observed on ventral side (Figs. 9H, K; 10C). Pairs of simple nerve and muscle openings of articulation for arm spine with border structures on external edge (Figs 9G, J; 10B). On middle to distal portion of arms, lateral arm plates carrying 5 or 6 articulations for hooklets on external edge beside the articulation for arm spine (Fig. 9J; 10B). On proximal to middle portion of arm, arm spines ovoid, with three projections, approximately one-thirds to one-fifth to one-sixth length of the height of spine (Fig. 9F). In distal portion, arm spines transformed into hooks with two inner secondary teeth (Fig. 10A). Hook-shaped arm spines distinguished from hooklets on dorsal and lateral surface of arm by lack of reticular structure (Figs. 9A, B, D; 10A).

All vertebrae with hourglass-shaped streptospondylous articulations (Figs. 10D, E; 11A, 12F, $\mathrm{G}$ ), and distal side of branching vertebra slightly wider than non-branching vertebra due to their possession of 2 articulation surfaces (Figs. 10H; 11C; 12C). Lateral furrows of vertebrae ornamented by tubercles in proximal to middle portion of arm, but smooth in distal portion of arm (Fig. 10F; 11D; 12B). Depressions for tube feet openings in distal part of ventral-lateral side of vertebrae (Figs. 10G, H; 11C; 12A). In proximal to middle arms, a pair of the channels for passages of lateral canals opening inside of ventral furrow, near depression of tube feet entire arms, and distal side of the channels, a pair of the channels for passage of lateral nerves opening (Figs. 10G, H; 11C). They are unrecognizable at distal portion of the arm (Figs. 10G, H; 11C; 12A, C).

\section{Distribution}

Confirmed records of Astrocladus dofleini: PHILIPPINES: Cabugan Grande Island, central Philippine, 135 m (Döderlein, 1927). JAPAN: Sagami Bay and Tokyo Bay, central-eastern Japan, 2-600 m (Döderlein, 1911; Irimura, 1982; Kohtsuka et al., 2016; this study, type locality, Fig. 1); Toyama Bay, central Japan, 40-80 m (Fujita and Kohtsuka, 2003); Tachibana Bay, Nagasaki, western Japan, ca. 40 m (This study, Fig. 1); off Minabe, Shirahama, Wakayama, central Japan, depth unknown (This study, Fig. 1). KOREA: Huksando, southwestern Korea, depth unknown (Yi \& Irimura, 1987).

\section{Discussion}

Döderlein (1902) described A. coniferus and A. pardalis on the basis of presence/absence of a large conical tubercle on the distal end of each radial shield. Subsequently, he determined that the presence/absence was an intra-specific character and the synonymized $A$. pardalis with $A$. coniferus 
432

433

434

435

436

437

438

439

440

441

442

443

444

445

446

447

448

449

450

451

452

453

454

455

456

457

458

459

460

(Döderlein, 1911).

In our study, although examinations of the lectotype of $A$. coniferus (ZSM 453/1) and the holotype of $A$. pardalis (ZSM 453/2) confirmed these morphological differences between the two specimens (Figs. 2E and 4C), monophyly of two additional specimens which morphologically agree with the lectotype of $A$. coniferus (NSMT E-13118) and the holotype of A. pardalis (NSMT E-13119) was confirmed by our molecular phylogeny (see also "Molecular phylogeny" below). Thus, we follow Döderlein's decision to synonymize these two species.

Döderlein (1911) also distinguished Astrocladus coniferus and A. dofleini as follow: A. coniferus possesses conical external ossicles but lacks large tubercles on dorsal surface of proximal portion of arms, whereas A. dofleini possesses only granules and large tubercles on the same position of the arms.

Matsumoto (1917) made the two species conspecific based on the existence of specimens showing intermediate features (Matsumoto, 1917) and Fujita and Kohtsuka (2003) followed this classification. Irimura (1982) distinguished A. coniferus (as "A. coniferus coniferus") and A. dofleini (as “A. coniferus var. dofleini”) based on presence/absence of large tubercles on dorsal surface of proximal arms. However, Irimura (1982) did not recognize any morphological features between the "A. coniferus var. dofleini" and A. pardalis (as "A. coniferus var. pardalis") except color differences.

In addition to the types of $A$. coniferus and $A$. pardalis, we also studied four paralectotypes (three specimens of ZSM 440/1 and ZMB 5923) of A. dofleini and confirmed that the Döderlein's diagnostic characters can not distinguish these species, because:

Ossicles on dorsal surface of proximal portion of arms were granular and conical in A. coniferus (Figs. 3A; 4F) and granular in A. dofleini (Fig. 8D). Both A. coniferus (Fig. 3A) and A. dofleini (Fig. 8D) possess large tubercles on dorsal surface of proximal arms.

Instead, A. coniferus can be distinguished from A. dofleini by the following three morphological characters:

1) Shape of ossicles: Ossicles on periphery of radial shields were conical in A. coniferus (Figs. 2F; 4D) but those of $A$. dofleini (Fig. 8C) were granules.

2) Shapes of large tubercles: Large tubercles on dorsal disc were conical in A. coniferus (Fig. 2F), whereas those of $A$. dofleini were all domed (Fig. 8C).

3) Distribution of the large tubercles: Although the large tubercles were only on the peripheral edges of radial shields (Fig. 2F) or absent (Fig. 4C) in A. coniferus, those of A. dofleini were scattered on the dorsal surface of the disc (Fig. 8C).

These differences were also recognized in other examined materials: 2 specimens of $A$. coniferus (NSMT E-13118 and NSMT E-13119); and 6 specimens of $A$. dofleini. Therefore, we conclude that A. coniferus and A. pardalis are conspecific and distinct from A. dofleini. Our molecular phylogenetic analysis also supports this conclusion (see "Molecular phylogeny" below). 
Additionally, color may also differ in these specimens. On the dorsal side, the 2 examined specimens of $A$. coniferus are vivid orange with yellow patches and arm bands, and the 6 NSMT specimens of $A$. dofleini are uniformly black with small black patches and arm bands, or yellow with light yellowish small patches and arm bands (Fig. 7). However, we refrain from employing these color variations as diagnostic characters because other color patterns for these species have been recorded (e.g. Irimura, 1982).

Astrocladus exiguus (Lamarck, 1816)

(Figs. 13-16)

Euryale exiguum Lamarck, 1816, 539.

Astrophyton exiguum.-Müller \& Troschel, 1842, 125; Lyman, 1875, pl. 4, fig. 48; 1882, 257, pl. 47, fig. 1. Astrocladus exiguus.-Doderlein, 1911, 76, 77, 106, 107, pl. 9, fig. 6; 1927, 34, 93, pl. 5 fig. 9; Clark H.L., 1915, 187; Koehler, 1931, 34, 35, pl. 4, figs. 1, 2; Chang et al., 1962, 59, 60, pl. 1, figs. 1, 2; Clark, A.M. \& Rowe, 1971, 78, 79, 92, fig. 21; Cherbonnier \& Guille, 1978, 11, 12, pl. 2, figs. 1, 2; Baker, 1980, 63, figs. 28, 33; Irimura, 1981, 19; Liao \& Clark, A.M., 1995, 169, 170, fig. 73, pl. 19, fig. 1; Rowe \& Gates, 1995, 365; Baker et al., 2018, 9, 10.

Gorgonocephalus cornutus Koehler, 1897, 368, 369, pl. 9, figs. 80, 81; 1899, 73, 74, pl. 12, figs. 95, 96, pl. 13, fig. 98 .

Astrophyton cornutum.-Koehler, 1905, 127-129, pl. 13, fig. 1, pl. 18, fig. 2.

Astrocladus dofleini.-Bomford, 1913, 220, 221, pl. 13, fig. 1 (Non Astrocladus dofleini).

\section{Material examined}

NSMT E-13125, 1 specimen, off Minabe, Wakayama, Japan, depth unknown, 11 November 2012, gill net. NSMT E-13126, 1 specimen, off Minabe, Wakayama, Japan, depth unknown, 4 April 2019, gill net, collected by Sadao Inoue. NSMT E-6265, off Yaku-shima Island, Kagoshima, Japan, $29^{\circ} 47.00^{`}$ N., $130^{\circ} 22.06^{\prime}$ E. 155-170 m, 2 August 2008, 1 m biological dredge, R/V Soyo-Maru of Japan Fisheries Research and Education Agency.

\section{Description of external morphology (NSMT E-13126)}

Disc. Disc five-lobed with notched interradial edges, approximately $26 \mathrm{~mm}$ in disc diameter. Radial shields and surrounding plates slightly tumid (Fig. 13B). Dorsal disc covered by variously sized conical ossicles, which bear spiny projections on their apices (Fig. 13A, B). The larger conical external ossicles separated and scattered, approximately $140-1150 \mu \mathrm{m}$ in length, having several thorny apical projections (Fig. 13A). Radial shields concealed by ossicles (Fig. 13B, C). One large tubercle situated on distal edge of each radial shield, approximately $1.7 \mathrm{~mm}$ in diameter (Fig. 13A). 
Ventral surface of disc covered by polygonal plate-like ossicles, fully in contact, approximately $170-500 \mu \mathrm{m}$ in length. Ossicles on ventral plates granule-shaped, approximately $130 \mu \mathrm{m}$ in length (Fig. 13C). Oral shields, adoral shields, oral plates and ventral arm plates concealed by ossicles (Fig. 13C-E). Teeth uniformly spiniform, situated on top of dental plates and edges of ventral plates (Fig. 13C). Teeth arranged in 1 or 2 transverse rows on ventral plates, approximately 10 in number (Fig. 13C), in a cluster covering ventral-most part of dental plate, approximately 15 in number (Fig. 13C), and in a vertical line, on other areas of dental plates, 2 in number. Size of teeth varying in position on oral and dental plate, approximately $0.3-1 \mathrm{~mm}$ in length, $0.3 \mathrm{~mm}$ in greatest width on dental plates, and $1 \mathrm{~mm}$ in length, approximately $0.2 \mathrm{~mm}$ in width on ventral plates (Fig. 13C).

Interradial surface of lateral disc covered by conical ossicles similar to those on dorsal disc (Fig. 13D). They are fully in contact, approximately $40-100 \mu \mathrm{m}$ in length (Fig. 13D). Two genital slits (0.9 mm long and $0.2 \mathrm{~mm}$ wide) in each interradius (Fig. 13D). One large, elliptical madreporite situated on ventral interradius, approximately $0.65 \mathrm{~mm}$ in width and $0.35 \mathrm{~mm}$ in length (Fig. 13D).

Arms. Arms branching. On proximal portion of arm, before first branch, arm $12.0 \mathrm{~mm}$ wide and $5.5 \mathrm{~mm}$ high, with an arched dorsal surface and flattened ventral surface. Between first branch and second branch, arm width and height abruptly decreasing to $4.3 \mathrm{~mm}$ in width and $3.0 \mathrm{~mm}$ in height. Subsequently, arms tapering gradually toward arm tip (Fig. 13E-J).

On dorsal and lateral surface of middle to distal portion of arms, each arm segment covered by single annular, ring-like row of large oblong plates, approximately $700 \mu \mathrm{m}$ in transverse length (Fig. 13I, J). Before third branch, each plate separated by granules. Plates fully in contact from fourth branch and on subsequent distal segments (Fig. 13I). Before third branch, no hooklets (Fig. 13H), after fifth branch, plates appearing and forming an annual band (Fig. 13I). With exception of hooklet-bearing plates, dorsal and lateral surface of arm completely covered by conical, plate-shaped and domed granule-shaped ossicles (Fig. 13H-I). Proximal portion of dorsal arm covered by conical ossicles similar to those on dorsal disc, approximately $0.3-1.5 \mathrm{~mm}$ in length slightly separated, and plate-shaped external ossicles, fully in contact, approximately $200 \mu \mathrm{m}$ in length (Fig. 13H). Middle portion of dorsal arm covered by domed granules, approximately $170-220 \mu \mathrm{m}$ in length, and plate-shaped ossicles, approximately $110 \mu \mathrm{m}$ in length (Fig. 13I). The larger conical ossicles sometimes carry spiny projections. Distal portion of dorsal arm covered by granule-shaped external ossicles, approximately $50 \mu \mathrm{m}$ in length (Fig. 13J). In proximal to middle portion of arms, ventral surface covered by polygonal and plate-shaped ossicles, similar to those on ventral disc, fully in contact, approximately $150-250 \mu \mathrm{m}$ in length at proximal region, and 60260 in length distally (Fig. 13H, I). Distal portion of ventral arm covered by granule-shaped external ossicles, slightly in contact, approximately $40 \mu \mathrm{m}$ in length (Fig. 13J). With exception of the articulations with arm spines and/or hooklets, lateral arm plates and ventral arm plates concealed by skin and ossicles (Fig. 13E-G). First to fifth tentacle pore without single spine; sixth pores with 1 spine, seventh and subsequent pore with 2 or 3 spines (Fig. 13E). Distally, the number of arm spines decrease gradually to 2 
540 toward arm tip (Fig. 13G). Arm spines approximately one-third to one-fourth of length (ca. 25-35\%) of 541 corresponding arm segment, covered by thin integument (Fig. 13E-G).

Color. Dorsal surface dark brown with whitish patches on disc and bands on arms. Ventral surface whitish but slightly brown on disc.

Ossicle morphology of NSMT E-13126: Each hooklet with single inner tooth and reticular structure (Fig. 14A, C). Hooklet-bearing plates with 4 tubercle-shaped articulations for hooklets in proximal portion of the arm (Fig. 14B), approximately 5 articulations in distal portion (Fig. 14D); articulations forming 2 parallel rows (Fig. 14B, D). Lateral arm plates long, both distal and proximal edges straight (Fig. 14E). On proximal portion of arm, lateral arm plates without perforation-like structures on dorsal side and pairs of simple nerve and muscle openings on ventral-external side (Fig. $14 \mathrm{E}, \mathrm{F})$ and on distal portion of arms, no perforation-like structure on dorsal side and a pair of nerve and muscle openings of articulation for arm spine beside boarder structure and 4 articulations for hooklets on ventral surfaces (Fig. 14G, H). Arm spines in proximal portion of arm ovoid, with four small projections, approximately one-third the height of the height of spine (Fig. 14I). In distal portion, arm spines transformed into hooks with 2 inner secondary teeth, respectively (Fig. 15A).

All vertebrae with hourglass-shaped streptospondylous articulations (Fig. 15B, C, G, H), and distal side of branching vertebra slightly wider than in non-branching vertebra and with 2 articulation surfaces (Figs. 15E; 16B). Surfaces of lateral furrows smooth, with no special ornamentation (Figs. 15F; 16A). Depressions for tube feet openings in distal part of ventral-lateral side of vertebrae (Figs.15D, E; 16C). Two pairs of the channels for passages of lateral canals and lateral nerves opening on ventral groove of vertebrae in proximal portion of arm (Fig. 15D, E). In distal portion of arm, only radial water canal observed (Fig. 16B). External ossicles on dorsal periphery of radial shields conical, approximately $150 \mu \mathrm{m}$ in length and $200 \mu \mathrm{m}$ in height with a spiny apical projection, approximately $100 \mu \mathrm{m}$ in length (Fig. 16D).

Distribution. Widely distributed in Indo-Western Pacific Ocean. Depth range 18-494 m.

\section{Discussion}

Astrocladus exiguus can be distinguished from other congeners by its covering of large tubercles and ossicles on dorsal surface of disc and proximal regions of arms: large tubercles are conical and scattered; ossicles conical with acute thorny tips (Table 2). Our molecular phylogeny showed that the two examined specimens of $A$. exiguus were monophyletic and distinguished from $A$. coniferus and A. dofleini (See "Molecular phylogeny" below). 
Astrocladus annulatus Matsumoto, 1912

(Fig. 17)

Astrophyton annulatum Matsumoto, 1912a: 206, figs. 17-18.

Astrocladus annulatus.-Matsumoto, 1912b: 389; 1915: 56-57; 1917: 75-77, fig. 22; Clark, H. L., 1915: 187; Irimura, 1981: 19; Irimura \& Kubodera, 1998: 138.

\section{Type material examined}

The holotype (UMUTZ-Oph-26): Off Misaki, Miura, Sagami Bay, Kanagawa, Japan, depth and collected data unknown, disc cut into two halves, probably done by Hikoshichiro Matsumoto (Fujita, 2006).

\section{Description of holotype (UMUTZ-Ophi-26)}

Disc. Disc five-lobed with notched interradial edges, $22 \mathrm{~mm}$ in diameter. Dorsal disc covered by granules, approximately 140-280 $\mu \mathrm{m}$ in length (Fig. 17B) Radial shields and their surrounds tumid, concealed by ossicles (Fig. 17A), approximately $1.1 \mathrm{~mm}$ in length, almost reaching disc center (Fig. 17A). Large domed tubercles, approximately $450 \mu \mathrm{m}$ in length scattered on radial shields (Fig. 17B).

Ventral surface of disc covered by polygonal plate-like ossicles, fully in contact, approximately 160-200 $\mu \mathrm{m}$ in length (Fig. 17D). Oral shields, adoral shields, oral plates and ventral arm plates concealed by ossicles (Fig. 17D). Teeth uniformly spiniform, on top of dental plates and edges of ventral plates (Fig. 17D). Teeth approximately 8, arranged in 1 or 2 transverse rows on ventral plates in a cluster covering ventral-most part of dental plate, approximately 10 in number (Fig. 17D). Size of teeth variable, approximately $1 \mathrm{~mm}$ in greatest length on dental plates, approximately $0.5 \mathrm{~mm}$ on oral plates (Fig. 17D). Interradial surface of lateral disc covered by thick skin (Fig. 17E). Two genital slits (4.5 mm long and 1 mm wide) in each interradius (Fig. 17E). One small, elliptical madreporite on ventral interradius.

Arms. Arms branching. On the proximal portion, before first branch, arm $4.3 \mathrm{~mm}$ wide and 3.5 $\mathrm{mm}$ high, with an arched dorsal surface and flattened ventral surface (Fig. 17A, C). Between first and second branch, arm width and height abruptly decreasing to $3 \mathrm{~mm}$ in width and $1.8 \mathrm{~mm}$ in height. Subsequently, arms tapering gradually toward arm tip (Fig. 17A, C).

On dorsal and lateral surface, each arm segment covered by single annular row of large oblong plates (Fig. 17G, H). With exception of hooklet-bearing plates, dorsal and lateral surface of arm completely covered by polygonal plate-like ossicles, approximately 170-290 in length at proximal portion of arms, and subsequently decreasing in size to arm tip (Fig. 17G, H). Ventral side of arms covered by skin which completely conceals the external ossicles, lateral arm plates and ventral arm plates, with exception of the part where lateral arm plates and arm spines articulating (Fig. 17I, J). Tentacle pores without arm spines before first branch; 3 or 4 spines after second branch. Distally, number of arm spines decrease gradually to 1 towards arm tip (Fig. 17J). In proximal portion, arm spines approximately one-

Peer] reviewing PDF | (2020:05:49200:1:2:CHECK 31 Jul 2020) 
610 fourth to one-fifth of length of corresponding arm segment, and covered by thin integument; subsequently

611 relative length increase, exceeding half length of corresponding arm segment on distal portion of arm 612 (Fig. 17J).

Color. Uniformly creamy white (Fig. 17).

615 Distribution. JAPAN: Sagami Sea, Off Misaki, Kanagawa, central-eastern Japan depth unknown 616 (Matsumoto, 1917); Seto, Wakayama, central Japan, depth unknown (Irimura, 1981); East China Sea, western Japan, 200 m (Irimura \& Kubodera, 1998).

\section{Discussion}

Astrocladus annulatus was originally described by Matsumoto (1912) based on the holotype collected from off Misaki, Sagami Bay. It has never been re-collected from the type locality and never re-described so far. In our examination of the holotype, we confirmed the diagnostic character of this species, namely granules on dorsal surface of body (Fig. 17B) and continuous hooklet-bearing plates on proximal portions of arms (Matsumoto, 1912; Table 2).

\section{Molecular phylogeny}

\section{Phylogenetic tree and assignation of species to each detected clade}

After removal of ambiguous aligned sites, $699 \mathrm{bp}$ of COI were obtained for 10 specimens. The ML tree of concatenated sequence is shown in Fig. 18. The Bayesian tree also showed the same topology. In the ML analyses, monophyly of the genus Astrocladus was weakly supported (Fig. 18, Clade 1, bootstrap 77\%, BPP 0.97). Within this clade, two clades (Fig. 18, Clade 2, bootstrap 99\%, BPP 1.00; Clade 3, bootstrap 99\%, BPP 1.00) were detected. The clade 3 was subdivided into two clades (Fig. 18, Clade 4, bootstrap 100\%, BPP 1.00; Clade 5, bootstrap 99\%, 0.99).

The specimens used in each clade were found to be identified as A. exiguus (Clade 2), A. dofleini (Clade 4) and A. coniferus (Clade 5), respectively (See also remarks of A. dofleini and A. exiguus above). $0.7 \%$ in A. dofleini (Clade 4, 3 specimens) and 1.3\% in A. coniferus (Clade 5, 3 specimens). Genetic distances were $13 \%$ between $A$. dofleini and A. coniferus, $14.7 \%$ between $A$. dofleini and A. exiguus, and $14.6 \%$ between $A$. coniferus and $A$. exiguus, respectively. Intra-clade distance ( 0.67 to $1.3 \%)$ was about ten folds smaller than inter-clade distance (13 to $14.7 \%$ ).

\section{Genetic distances}

Mean genetic distances within each clade were $0.67 \%$ in $A$. exiguus (Clade 2, 3 specimens), 
646

647

648

649

650

651

652

653

654

655

656

657

658

659

660

661

662

663

664

665

666

667

668

669

670

671

672

673

674

675

676

677

678

679

680

681

Our molecular phylogenetic analyses suggest that A. exiguus, A. coniferus and A. dofleini should be assigned to separate taxa. Genetic distance analysis showed that the inter-clade distances exceed intra-clade values. In previous studies of ophiuroids, genetic distance corresponding to species differences range from approximately 2.2 to $23 \%$ (e.g. Okanishi et al., 2018). Therefore, the distances between current clades (13 to $14.7 \%$ ) are within this range.

In our analysis, we found that $A$. coniferus and A. dofleini form a clade (Clade 3). Therefore, a possible classification would be to unite A. coniferus and A. dofleini as the same species (A. coniferus) and subdivide A. coniferus coniferus and A. coniferus dofleini under A. coniferus, as has been done in the past (e.g. Fedotov, 1926; Irimura, 1982). However, since the genetic distance between A. dofleini and A. coniferus is comparable to the distance of the two species from A. exiguus, which is considered to be a separate species in terms of morphology, A. dofleini and A. coniferus are herein shown to be separate species.

\section{Conclusions}

In the present study, morphological observations of type and non-type specimens revealed that Astrocladus pardalis (Döderlein, 1902) is a junior synonym of A. coniferus (Döderlein, 1902). Morphological observations and molecular phylogenetic analysis revealed that $A$. coniferus and $A$. dofleini (Döderlein, 1910) are different species. Therefore, 4 species, A. annulatus, A. coniferus, A. dofleini and A. exiguus occurin Japan. Additional molecular analyses including A. annulatus and examination of type specimens of $A$. exiguus are required to finally clarify the taxonomy of Japanese basket stars of the genus Astrocladus.

\section{Acknowledgements}

We are most grateful to David L. Pawson of National Museum of Natural History, Smithsonian Institution for his critical reading of the manuscript and constructive comments, and to Bernhard Rüthensteiner of the Zoologische Staatssammlung München, Peter Bartsch of Museum für Naturkunde der Humboldt-Universität zu Berlin and to Rei Ueshima The University Museum, The University of Tokyo for their help in observation of specimens. Thanks are also extended to the captains and crew members of the R/V Soyo-Maru of Japan Fisheries Research and Education Agency, and colleagues on board for their assistance in collecting the specimens, and Tetsuya Kato and Keita Harada of Kyoto University Aquarium, their providing specimens. This work was partly supported by a grant from the Research Institute of Marine Invertebrates, KAKENHI Grant Numbers 125750008, 22570104, 25440226, 17K07549, and by the integrated research, "Geological, biological, and anthropological histories in relation to the Kuroshio Current" and "Spatiotemporal Analyses on Origins and Properties of the Biodiversity Hotspots in Japan", conducted by the National Museum of Nature and Science.

\section{References}


682

683

684

685

686

687

688

689

690

691

692

693

694

695

696

697

698

699

700

701

702

703

704

705

706

707

708

709

710

711

712

713

714

715

716

717

Baker AN. 1980. Euryalinid Ophiuroidea (Echinodermata) from Australia, New Zealand, and the southwest Pacific Ocean. New Zealand Journal of Zoology 7:73.

Baker AN, Okanishi M, Pawson DL. 2018. Euryalid brittle stars from the International Indian Ocean Expedition 1963-64 (Echinodermata: Ophiuroidea: Euryalida). Zootaxa 4392:1-27.

Bergsten J. 2005. A review of long-branch attraction. Cladistics 21:163-193. DOI: 10.1111/j.10960031.2005.00059.x LB

Bomford TL. 1913. A note on certain ophiurans in the Indian Museum. Records of the Indian Museum 9:215-225.

Chang FY, Liao YL, We BL. 1962. Euryalae of the China Sea. Acta Zoologica Sinica 14:53-68.

Cherbonnier G, Guille A. 1978. Faune de Madagascar. 48. Echinodermes: Ophiurides. Paris: Editions du Centre National de la Recherche Scientifique.

Christodoulou M, O’Hara TD, Hugall AF, Arbizu PM. 2019. Dark ophiuroid biodiversity in a prospective abyssal mine field. Current Biology 29:3909-3912.e3. DOI: 10.1016/j.cub.2019.09.012.

Clark HL. 1911. North Pacific Ophiurans in the collection of the United States National Museum. Smithsonian Institution United States National Museum Bulletin 75:1-302.

Clark HL. 1915. Catalogue Of recent Ophiurans: Based on the Colletion of the Museum of Comparative Zoology. Memorians of the Museum of Comparative Zoölogy at Havard College XXV:165-376.

Clark HL. 1923. The echinoderm fauna of South Africa. Annals of the South African Museum 13:221435.

Clark AM. 1951. Some echinoderms from South Africa. Transactions of the Royal Society of South Africa 33:193-221. DOI: 10.1080/00359195109519884.

Clark AM. 1974. Notes on some echinoderms from southern Africa. Bulletin of the British Museum (Natural History), Zoology 26:421-487.

Clark AM, Courtman-Stock J. 1976. The echinoderms of southern Africa. London: British Museum (Naturak History).

Clark AM, Rowe FWE. 1971. Monograph of shallow-water Indo-West Pacific Echinoderms. London: British Museum (Natural History).

Djakonov AM. 1954. Ophiuroids of the USSR Seas. In: Pavlovskii EN ed. Keys to the fauna of the USSR. Jerusalem: Wiener Bindery Ltd., 1-123.

Döderlein L. 1896. Bericht über die von Herrn Professor Semon bei Amboina und Thursday Island gesammelten Ophiuroidea. Denkschriften der Medicinisch-Naturwissenschaftichen Gesellschaft zu Jena 8:279-300.

Döderlein L. 1902. Japanische Euryaliden. Zoologischer Anzeiger 25.

Döderlein L. 1910. Forschungsreise im westlichen und zentralen Sudafrika 4 (1). Asteroidea, Ophiuroidea, Echinoidea. Denkschriften der medicinisch-naturwis-senschaftlichen Gesellschaft zu

Peer) reviewing PDF | (2020:05:49200:1:2:CHECK 31 Jul 2020) 
Jena 16: 245-258.

Döderlein L. 1911. Über japanische und andere Euryalae. Abhandlungen der math. phys. Klasse der K. Bayer Akademie der Wissenschaften, Suppl. 5:1-123.

Döderlein L. 1912. Die arme der Gorgonocephalinae. Zoologische Jahrbücher Supplement 15:257-274.

Döderlein L. 1927. Indopacifische Euryalae. Abhandlungen der Bayerische Akademie der Wissenschaften, Mathematisch - naturwissenschaftiche Abteilung 31:1-105.

Fedotov DM. 1926. Die morphologie der Euryalae. Zeitschrift für wissenschaftliche Zoologie 127:403528.

Fell HB. 1960. Synoptic key to the genera of Ophiuroidea. Zoology Publications from Victoria University, Wellington 26:1-44.

Fujita T, Ishida Y, Kato T, Irimura S. 2004. Ophiuroids (Echinodermata) collected from the Oki Islands in the Sea of Japan. Bulletin of the National Science Museum, Series A, Zoology 30:191-218.

Fujita T, Kohtsuka H. 2003. Ophiuroids (Echinodermata) from Notojima Island and its adjacent waters in the Sea of Japan. Report of the Noto Marine Center 9:25-38.

Gouy M, Guindon S, Gascuel O. 2010. Sea View version 4 : a multiplatform graphical user interface for sequence alignment and phylogenetic tree building. Molecular Biology and Evolution 27:4.

Gray JE. 1840. Room II. In: Synopsis of the Contents of the British Museum. London, 57-65.

Guille A. 1981. Résultats des campagnes MUSORSTOM: 1. Philippines (18-28 Mars 1976). Mémoires du Muséum national d'Histoire naturelle. Série A, Zoologie 91:413-456.

Hasegawa M, Kishino H, Yano T. 1985. Dating of the human-ape splitting by a molecular clock of mitochondrial DNA. Journal of Molecular Evolution 22:160-174. DOI: 10.1007/BF02101694.

Hendler G. 2018. Armed to the teeth: A new paradigm for the buccal skeleton of brittle stars (Echinodermata: Ophiuroidea). Contributions in Science 526:189-311.

Irimura S. 1968. Preliminary report of ophiuroids on Tanabe Bay and adjacent waters. Nankiseibutu: The Nanki Biological Society 10:30-38.

Irimura S. 1969. Supplementary report of Dr. Murakami's paper on the ophiurans of Amakusa, Kyushu. Publications from the Amakusa Marine Biological Laboratory, Kyushu University 2:37-48.

Irimura S. 1979. Ophiuroidea of Sado Island, the Sea of Japan. Annual Report of the Sado Marine Biological Station, Niigata University 9:1-6.

Irimura S. 1981. Ophiurans from Tanabe Bay and its vicinity, with the description of a new species of Ophiocentrus. Publications of the Seto Marine Biological Laboratory 26:15-49.

Irimura S. 1982. The brittle-stars of Sagami Bay, collected by His Majesty the Emperor of Japan. Japan: Biological Laboratory, Imperial Household.

Irimura S. 1990. Echinoderms from continental shelf and slope around Japan Vol.I. In: The Intensive Research of Unexploited Fishery Resources on Continental Slopes. Tokyo: Japan Fisheries Resource Conservation Association, 65-100. 
Irimura S, Kubodera T. 1998. Ophiuroidea in the East China Sea. Memoirs of the National Science Museum 30:135-143.

Irimura S, Tachikawa H. 2002. Ophiuroids from the Ogasawara Islands (Echinodermata: Ophiuroidea). Ogasawara Research 28:1-27.

Ishida Y, Ohtsuka S, Takayasu K, Kobayashi I, Lee Y-G, Tanaka H, Tamura K, Go A, Nakaguchi K. 2001. Preliminary Fauistic survey of Ophiuroids in the Westernmost Part of the Sea of Japan. Journal of the Faculty of Applied Biological Science, Hokkaido University 40:14.

Jangoux M, de Ridder C, Fechter H. 1987. Annotated catalogue of recent echinoderm type specimens in the collection of the Zoologische Staatssammlung München. Spixiana 10:295-311.

Kimura M. 1980. A simple method for estimating evolutionary rates of base substitutions through comparative studies of nucleotide sequences. Journal of Molecular Evolution 16:111-120. DOI: 10.1007/BF01731581.

Koehler R. 1897. Échinoderms recueillis par “L'Investigator” dans l'Ocean Indian. Annales des Scienes Naturelles Zoologie et Paléontologie 4:277-371.

Koehler R. 1905. Ophiures de l'Expédition du Siboga. Part II. Ophiures de mer profonde. SibogaExpeditie 45b:1-142.

Koehler R. 1907. Revision de la collection des Ophiures du Museum d'histoire Naturelle Paris. Bulletin Scientifique de la Franca et de la Belgique 41:279-351.

Koehler R. 1930. Ophiures recueillies par le Docteur Th. Mortensen dans les Mers d'Australie et dans l'Archipel Malais. Papers from Dr. Th. Mortensen's Pacific Expedition 1914-16. LIV. Videnskabelige Meddelelser fra Dansk naturhistorisk Forening 89:1-295.

Kohtsuka H, Sekifuji M, Omori A, Okanishi M. 2017. Records of young basket stars, Astrocladus coniferus (Döderlein , 1902) from Misaki, Kanagawa Prefecture. Bulletin of the Biogeographical Society of Japan 71:229-235.

Kumar S, Stecher G, Li M, Knyaz C, Tamura K. 2018. MEGA X: Molecular evolutionary genetics analysis across computing platforms. Molecular Biology and Evolution 35:1547-1549. DOI: 10.1093/molbev/msy096.

Lamarck J-B. 1816. Ordre Second. Radiaires Échinodermes. Histoire Naturelle des Animaux Sans Vertèbres 2:522-568.

Liao Y, Clark AM. 1995. The echinoderms of southern China. Beijing, New York: Science Press. Ljungman A V. 1867. Ophiuroidea viventia huc usque cognita enumerat. In: Öfversigt af Kgl. Vetenskaps-Akademiens Förhandlingar. 221-272.

Lyman T. 1875. Zoological Results of the Hassler Expedition. 2. Ophiuridae and Astrophytidae. Illustrated catalogue of the Museum of Comparative Zoology at Harvard College 8:1-34.

Lyman T. 1882. Report on the Opiuroidea. Report of the Scientific Results of the voyage of H.M.S. Challenger 1873-76. Zoology 5:1-386. 
Matsumoto H. 1912a. Nihon san tedurumoduru ka ni tsuite [About Japanese Gorgonocephalidae]. Dobutsu gaku zasshi [Zoological Magazine] 282:198-206.

Matsumoto H. 1912b. Nihon san tedurumoduru rui no saisa [Revision of Japanese Euryalida]. Dobutsu gaku zasshi [Zoological Magazine] 285:379-390.

Matsumoto H. 1915. A new classification of the Ophiuroidea: with descriptions of new genera and species. Proceedings of the Academy of Natural Sciences of Philadelphia 67:43-92.

Matsumoto H. 1917. A monograph of Japanese Ophiuroidea, arranged according to a new classification. Journal of the College of Science Imperial University Tokyo 38:1-408.

McKnight DG. 1989. Some echinoderm records from the tropical Southwest Pacific Ocean. Department of Scientificand Industrial Research, Division of Marine and Freshwater Science (Wellington) Report 3:19-30.

McKnight DG. 2000. The marine fauna of New Zealand: basket-stars and snake-stars (Echinodermata: Ophiuroidea: Euryalinida). NIWA Biodiversity Memoir 115:79.

Mortensen T. 1933. Echinoderms of South Africa (Asteroidea: Ophiuroidea). Veidenskabelige Meddelelser fra Dansk Naturhistorisk Forening i Kjobenhavn 93:215-400.

Müller J, Troschel FH. 1842. System der Asteriden.1. Asteriae. 2. Ophiuridae. Braunschweig: Vieweg. Murakami S. 1944a. Note on the ophiurans of Amakusa, Kyusyu. Journal of the Department of Agriculture, Kyushu Imperial University 7:259-281.

Murakami S. 1944b. Report on the Ophiurans from off Ogasawara Islands and from off the Yaeyama Group, Nippon. Journal of the Department of Agriculture, Kyusyu Imperial University 7:235-257.

O’Hara TD, Hugall AF, Thuy B, Stöhr S, Martynov A V. 2017. Restructuring higher taxonomy using broad-scale phylogenomics: The living Ophiuroidea. Molecular Phylogenetics and Evolution 107:415-430. DOI: 10.1016/j.ympev.2016.12.006.

Okanishi M. 2016. Euryalida. AccessScience. DOI: https://doi.org/10.1036/1097-8542.246500.

Okanishi M, Fujita T. 2013. Molecular phylogeny based on increased number of species and genes revealed more robust family-level systematics of the order Euryalida (Echinodermata: Ophiuroidea). Molecular Phylogenetics and Evolution 69:566-580. DOI: 10.1016/j.ympev.2013.07.021.

Okanishi M, Fujita T. 2018. Description of a New Subfamily, Astrocloninae (Ophiuroidea: Euryalida: Gorgonocephalidae), Based on Molecular Phylogeny and Morphological Observations. Zoological Science 35. DOI: 10.2108/zs170090.

Okanishi M, O'Hara TD, Fujita T. 2011. Molecular phylogeny of the order Euryalida (Echinodermata: Ophiuroidea), based on mitochondrial and nuclear ribosomal genes. Molecular Phylogenetics and Evolution 61. DOI: 10.1016/j.ympev.2011.07.003.

Okanishi M, Yamaguchi K, Horii Y, Fujita T. 2011. Ophiuroids of the order Euryalida (Echinodermata) from Hachijōjima Island and Ogasawara Islands, Japan. Memoirs of the National Museum of Nature and Science 47:367-385. 
Retzius AJ. 1783. Anmärkningar vid. Asteriae genus. Kungliga Svenska Vetenskaps Akademiens Nya Handlingar 4:230-248.

Rho BJ, Shin S. 1987. Systematic study on the Ophiuroidea from Cheju Island, Korea. The Korean Journal of Systematic Zoology 3:208-224.

Rowe FWE, Gates J. 1995. Echinodermata. In: Wellis A ed. Zoological catalogue of Australia. Australia, Melbourne: CSIRO, 1-510.

Saba M, Tomida Y, Kimoto T. 1982. Echinoderms fauna of Ise Bay, and the northern and the middle parts of Kumano-nada. Bulletin of the Mie Prefectural Museum, Natural Science 4:1-82.

Shin S. 1992. A Systematic Skdy on the Ophiuroidea in Korea II. Cheiu Island. Korean Journal of Zoology 35:350-361.

Shin S, Rho BJ. 1996. Echinodermata. Seoul: Ministry of Education.

Stamatakis A. 2014. RAxML version 8: a tool for phylogenetic analysis and post-analysis of large phylogenies. Bioinformatics 30:1312-1313. DOI: 10.1093/bioinformatics/btu033 LB Stamatakis2014.

Stöhr S, O’Hara TD, Thuy B. 2012. Global diversity of brittle stars (Echinodermata: Ophiuroidea). PLoS ONE 7. DOI: 10.1371/journal.pone.0031940.

Tamura K, Nei M. 1993. Estimation of the number of nucleotide substitutions in the control region of mitochondrial DNA in humans and chimpanzees. Molecular Biology and Evolution 10. DOI: 10.1093/oxfordjournals.molbev.a040023.

Thompson JD, Higgins DG, Gibson TJ. 1994. CLUSTAL W: improving the sensitivity of progressive multiple sequence alignment through sequence weighting, position-specific gap penalties and weight matrix choice. Nucleic Acids Research 22:4673-4680.

Thuy B, Stöhr S. 2011. Lateral arm plate morphology in brittle stars (Echinodermata: Ophiuroidea): new perspectives for ophiuroid micropalaeontology and classification. Zootaxa 3013:47.

Verrill AE. 1899. North American Ophiuroidea. I. Revision of certain families and genera of West Indian ophiurans. Transactions of the Connecticut Academy Arts and Sciences 10:301-371.

Yi SK, Irimura S. 1987. A taxonomic study on the Ophiuroidea from the Yellow Sea. The Korean Journal of Systematic Zoology 3:117-136.

\section{Figure legends}

Figure 1. Sampling sites of Astrocladus annulatus, $A$. coniferus, $A$. dofleini and $A$. exiguus. Numerals indicate serial specimen number in Table 1.

Figure 2. Astrocladus coniferus, lectotype (ZSM 453/1).

(A) External view of lectotype bottle. (B) Labels of the lectotype. (C) Dorsal view. (D) Ventral view. (E) 
Dorsal disc and proximal portion of arm. (F) Dorsal periphery of one radius of disc. (G) Ventral disc and proximal to middle portion of arm. (H) Ventral interradial disc. Abbreviations: G, genital slit; M, madreporite; $\mathrm{T}$, large tubercle.

Figure 3. Astrocladus coniferus, lectotype (ZSM 453/1).

(A) Dorsal proximal portion of arm. (B) Dorsal middle portion of arm. (C) Ventral proximal portion of arm. (D) Ventral middle portion of arm. Arrowheads indicate rows of hooklets on dorsal and lateral side of the arms (A, B). Abbreviations: AS, arm spine; T, large tubercle.

Figure 4. Astrocladus coniferus, holotype of Astrophyton pardalis (ZSM 453/2) (A-F) and NSMT E13118 (G, H).

(A) Dorsal view. (B) Labels of the holotype. (C) Dorsal disc and proximal portion of arm. (D) Dorsal periphery of radial shield (E). Ventral disc. (F) Dorsal proximal portion of arm, partly enlarged. (G, H) live specimens, dorsal $(\mathrm{G})$ and ventral $(\mathrm{H})$ views.

Figure 5. Astrocladus coniferus (NSMT E-13118). SEM photographs of ossicles.

(A-C) Hooklets on proximal (A), middle (B) and distal (C) portion of arm, arcs indicate reticular structure. (D) Hooket-bearing plate on proximal portion of arm. (E, F) Lateral arm plates on proximal portion of arm, internal (E) and external (F) views. (G, H) Arm spines from proximal portion of arm, inner most $(\mathrm{G})$ and second inner most $(\mathrm{H})$. (I, J) Lateral arm plates on middle portion of arm, distal (I) and internal (J) views. (K, L) Arm spines on middle portion of arms, inner most $(\mathrm{K})$ and second inner most (L). Arrowheads indicate articulations for hooklets (D) and terminal projections (G, H, K, L). Orientations: dis, distal side; ex, external side; in, internal side; prox, proximal side. Abbreviations: MO, muscle opening; NO, nerve opening; P, perforation; ST, secondary tooth.

Figure 6. Astrocladus coniferus (NSMT E-13118). SEM photographs of ossicles.

(A, B) Lateral arm plates on distal portion of arm, external (A) and internal (B) views. (C) Hook-shaped arm spine on distal portion of arm. (D-G) Vertebrae from proximal (D, E) and middle (F, G) portion of arm, distal (D, G), ventral (E) and proximal (F) views. An arrowhead indicates articulation for hooklet (A). Abbreviations: AAS, articulation for arm spine; B, border structure; LN, passage of lateral canal; NO, nerve opening; ST, secondary tooth.

\section{Figure 7. Astrocladus coniferus (NSMT E-13118). SEM photographs of ossicles.}

Vertebrae from middle (A, B) and distal (C-F) portion of arm, ventral (A, E), dorsal (B, F), proximal (C) and distal (D) views. Orientations: d, dorsal side; dis, distal side; prox, proximal side; v, ventral side. Abbreviations: DT, depression for tentacle; LC, passages of lateral canal; LN, passages of lateral nerve; 
T, tubercle.

\section{Figure 8. Astrocladus dofleini, lectotype (440/1 lecto).}

(A) External view of lectotype bottle. (B) Labels of the lectotype. (C) Dorsal disc and proximal portion of arm. (D) Dorsal proximal portion of arm, partly enlarged in upper right. (E) Interradial ventral disc. (F) Dorsal middle to distal portion of arm. (G) Ventral disc and proximal portion of arm. (H) Ventral middle to distal tips of arm. Abbreviation: $G$, genital slit.

\section{Figure 9. Astrocladus dofleini (NSMT E-13124). SEM photographs of ossicles.}

(A, B, D) Hooklets on proximal (A), middle (B) and distal (D) portion of arms, arcs indicate reticular structure. (C, E) Hooket-bearing plate on proximal (C) and distal (E) portion of arm. (F, I) Arm spines on proximal (F) and middle (I) portion of arms. (G, H, J, K) Lateral arm plates on proximal (G, H) and middle $(\mathrm{J}, \mathrm{K})$ portion of the arms, external $(\mathrm{G}, \mathrm{J})$ and internal $(\mathrm{H}, \mathrm{K})$ views. Arrowheads indicate articulations of hooklets (C, E, J) and terminal projections (F). Orientations: d, dorsal side; dis, distal side; ex, external side; in, internal side prox, proximal side; v, ventral side. Abbreviations: AAS, articulation for arm spine; $\mathrm{B}$, border structure; $\mathrm{MO}$, muscle opening; $\mathrm{NO}$, nerve opening; ST, secondary tooth.

Figure 10. Astrocladus dofleini (NSMT E-13124). SEM photographs of ossicles.

(A) An arm spine from distal portion of arm. (B, C) Lateral arm plates on distal portion of arm, external (B) and internal (C) views. (D-H) Vertebrae from proximal portion of arm ( $\mathrm{H}$ is branching vertebra), distal (D), proximal (E), dorsal (F) and ventral (G, H) views. Orientations: d, dorsal side; dis, distal side; prox, proximal side; v, ventral side. Arrowheads indicate articulations for hooklets. Abbreviations: B, boarder structure; DT, depression for tentacle; LC, passages of lateral canal; LN, passages of lateral nerve; MO, muscle opening; ST, secondary tooth; T, tubercle.

\section{Figure 11. Astrocladus dofleini (NSMT E-13124). SEM photographs of ossicles.}

(A-E) Vertebrae from middle portion of arm (C is branching vertebra), distal (A), ventral (B, C), dorsal (D) views, a part of (D) enlarged in (E). Vertebrae from distal portion of arm (F, G), distal (F) and proximal (G)views. Orientations: d, dorsal side; dis, distal side; prox, proximal side; v, ventral side. Arrowheads indicate tubercles on lateral furrow of vertebra. Abbreviations: DT, depression for tentacle; LC, passages of lateral canal; LN, passages of lateral nerve; T, tubercle.

\section{Figure 12. Astrocladus dofleini (NSMT E-13124).}

SEM photographs of vertebrae from distal portion of arm (C is branching vertebra), ventral $(\mathrm{A}, \mathrm{C})$ and dorsal (B) views. Orientations: dis, distal side; prox, proximal side. Abbreviation: DT, depression for 
934

935

936

937

938

939

940

941

942

943

944

945

946

947

948

949

950

951

952

953

954

955

956

957

958

959

960

961

962

963

964

965

966

967

968

969

tentacle.

\section{Figure 13. Astrocladus exiguus (NSMT E-13126).}

(A) Periphery of dorsal disc. (B) Central view of dorsal disc. (C) Ventral disc. (D) Interradial ventral disc. (E-G) Ventral surfaces of arms, proximal (E), middle (F) and distal (G) portion of arm. Dorsal surfaces of arms, proximal (H), middle (I) and distal (J) portion of arm. Arrowheads indicate rows of hooklets on dorsal and lateral side of the arms (I, J). Abbreviations: AS, arm spine; G, genital slit; M, madreporite; T, large tubercle. Photographs of this figure were focus-stacked using the software CombineZM $\quad$ v. $\quad 1.0 .0 \quad$ (https://www.softpedia.com/get/Multimedia/Graphic/GraphicEditors/CombineZM.shtml).

\section{Figure 14. Astrocladus exiguus (NSMT E-13126). SEM photographs of ossicles.}

(A, C) Hooklets on proximal (A) and distal (C) portion of arms, arcs indicate reticular structure. (B, D) Hooket-bearing plate on proximal (B) and distal (D) portion of arm. (E-H) Lateral arm plates on proximal $(\mathrm{E}, \mathrm{F})$ and distal $(\mathrm{G}, \mathrm{H})$ portion of arms. (I) An arm spine on proximal portion of arm. Arrowheads indicate articulations for hooklets $(\mathrm{B}, \mathrm{D}, \mathrm{H})$ and terminal projections (I). Orientations: $\mathrm{d}$, dorsal side; dis, distal side; ex, internal side; in, internal side; prox, proximal side; v, ventral side. Abbreviations: AAS, articulation for arm spine; B, border structure; MO, muscle opening; NO, nerve opening; ST, secondary tooth.

\section{Figure 15. Astrocladus exiguus (NSMT E-13126). SEM photographs of ossicles.}

(A) An arm spine on distal portion of arm. (B-F) Vertebrae from proximal portion of arm (E is branching vertebra), proximal (B), distal (C), ventral (D, E) and dorsal (F) views. $(G, H)$ Vertebrae from distal portion of arm, proximal $(\mathrm{G})$ and distal $(\mathrm{H})$ views. Orientations: d, dorsal side; dis, distal side; prox, proximal side; v, ventral side. Abbreviations: DT, depression for tentacle; LC, passages of lateral canal; LN, passages of lateral nerve; ST, secondary tooth.

\section{Figure 16. Astrocladus exiguus (NSMT E-13126). SEM photographs of ossicles.}

$(A-C)$ Vertebrae from distal portion of arm (B is branching vertebra), dorsal (A), ventral (B, C) views. (D) An conical external ossicle on proximal portion of arm, lateral view, an arc indicates a terminal projection. Orientations: ba, basal side; dis, distal side; ex, external side; prox, proximal side. Abbreviations: DT, depression for tentacle; LC, passages for lateral canals.

\section{Figure 17. Astrocladus annulatus, holotype (UMUTZ-Ophi-26).}

(A) Dorsal view. (B) Dorsal surface of periphery disc (C) Ventral view. (D) Jaws. (E) Interradial ventral disc. $(\mathrm{F}-\mathrm{H})$ Dorsal surface of arms, proximal $(\mathrm{F})$, middle $(\mathrm{G})$ and distal $(\mathrm{H})$ portion of arm. (I, J) 
970 Ventral surface of arms, proximal (I) and distal (J) portion of arm. Arrowheads indicate rows of 971 hooklets on dorsal and lateral side of the arms (B, G, H). Abbreviations: AS, arm spine; G, genital slit.

972

Figure 18. Maximum likelihood tree based on a partial sequence of mitochondrial COI gene (699 bp).

Support values for each node are shown by maximum likelihood bootstrap values (\%) and Bayesian posterior probabilities. Numerals (1-5) in circles at nodes refer to the clade number discussed in the text. Bootstrap value less than $74 \%$ and Bayesian posterior probability value less than 0.97 and for each node were shown by as “-”.

\section{Table 1:}

\section{Examined specimens of Astrocladus species including outgroup.}

COI accession numbers are lodged at the DNA Data Bank of Japan. See referees for the detailed information. Unknown data are shown by “-”. Abbreviations: NSMT, the National Museum of Nature and Science, Tsukuba, Japan; UMUT, The University Museum, The University of Tokyo, Japan; ZMB, Museum für Naturkunde der Humboldt-Universität zu Berlin, Germany; ZSM, the Zoologische Staatssammlung München, Germany.

\section{Table 2.}

\section{Tabular key to the species of the Astrocladus in Japanese waters.}

Tabular morphological characteristic key to Astrocladus annulatus, A. coniferus, A. dofleini and A. exiguus in Japanese waters. 
Figure 1

Sampling sites of Astrocladus annulatus, A. coniferus, A. dofleini and A. exiguus.

Numerals indicate serial specimen number in Table 1. 
FIGURE 1

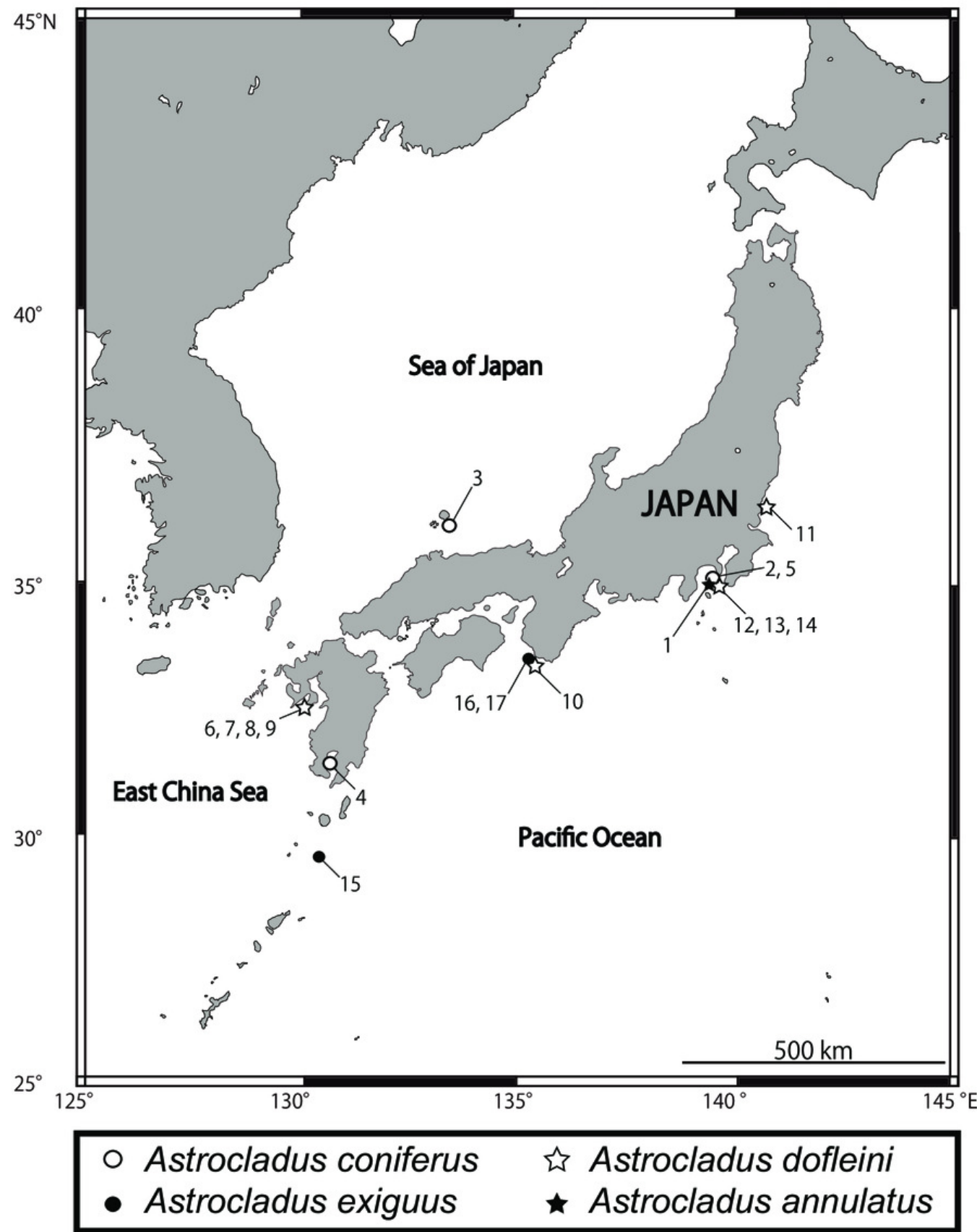


Figure 2

Figure 2. Astrocladus coniferus, lectotype (ZSM 453/1).

(A) External view of lectotype bottle. (B) Labels of the lectotype. (C) Dorsal view. (D) Ventral view. (E) Dorsal disc and proximal portion of arm. (F) Dorsal periphery of one radius of disc. (G) Ventral disc and proximal to middle portion of arm. $(\mathrm{H})$ Ventral interradial disc. Abbreviations: G, genital slit; $M$, madreporite; $T$, large tubercle. 


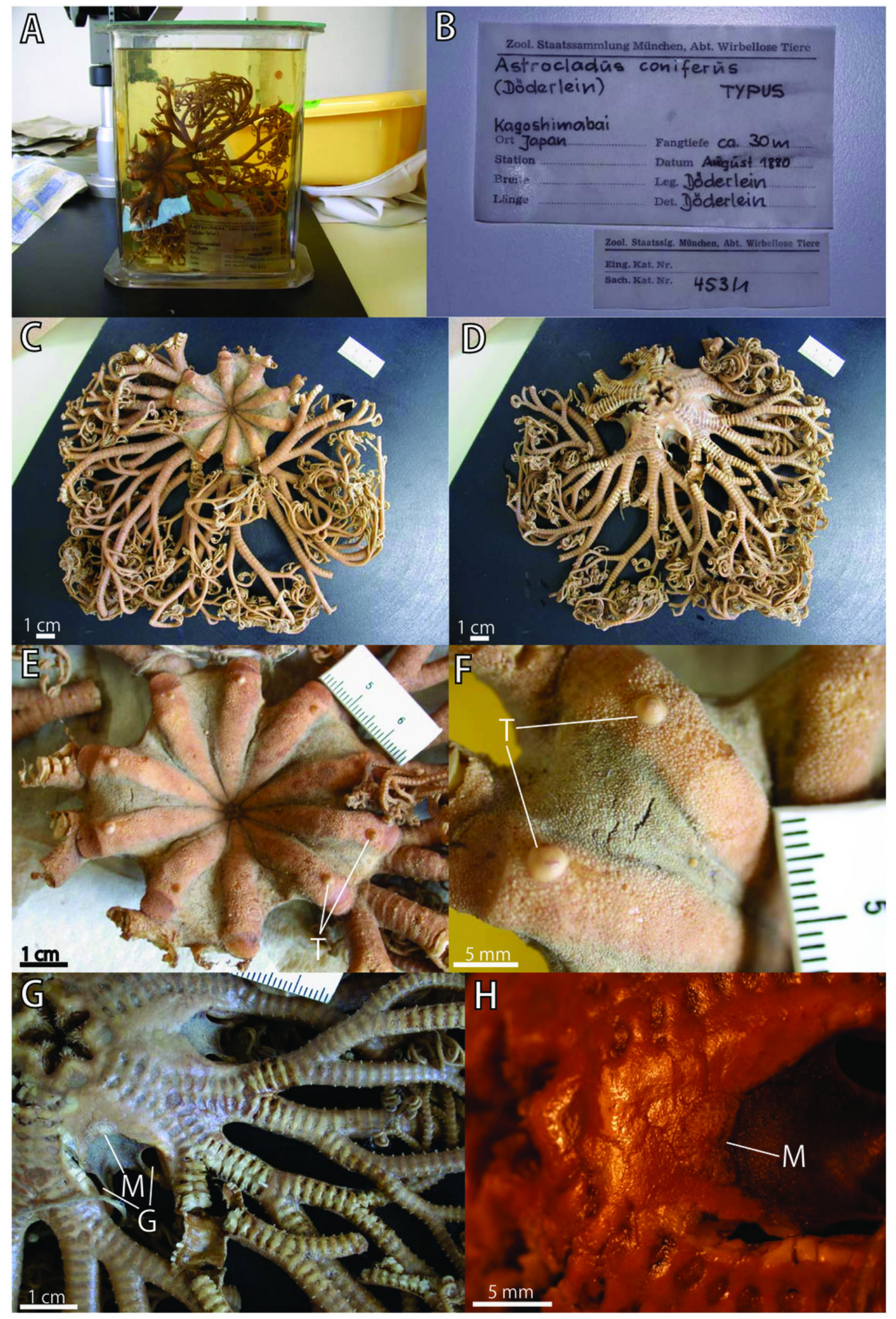




\section{Figure 3}

Figure 3. Astrocladus coniferus, lectotype (ZSM 453/1).

(A) Dorsal proximal portion of arm. (B) Dorsal middle portion of arm. (C) Ventral proximal portion of arm. (D) Ventral middle portion of arm. Arrowheads indicate rows of hooklets on dorsal and lateral side of the arms (A, B). Abbreviations: AS, arm spine; T, large tubercle. 


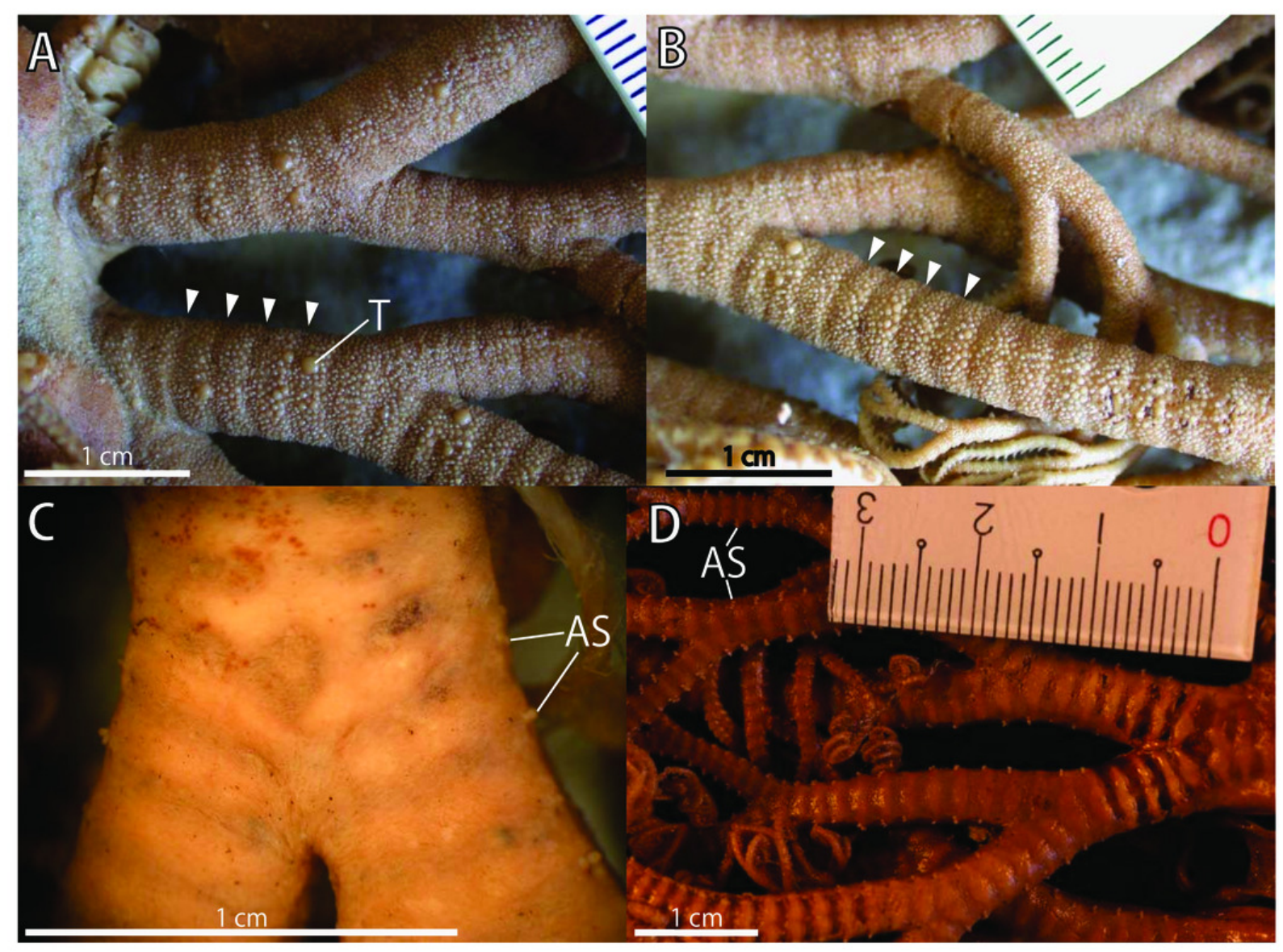


Figure 4

Figure 4. Astrocladus coniferus, holotype of Astrophyton pardalis (ZSM 453/2) (A-F) and MO-2018-118A (G, H).

(A) Dorsal view. (B) Labels of the holotype. (C) Dorsal disc and proximal portion of arm. (D) Dorsal periphery of radial shield (E). Ventral disc. (F) Dorsal proximal portion of arm, partly enlarged. $(G, H)$ live specimens, dorsal $(G)$ and ventral $(H)$ views. 


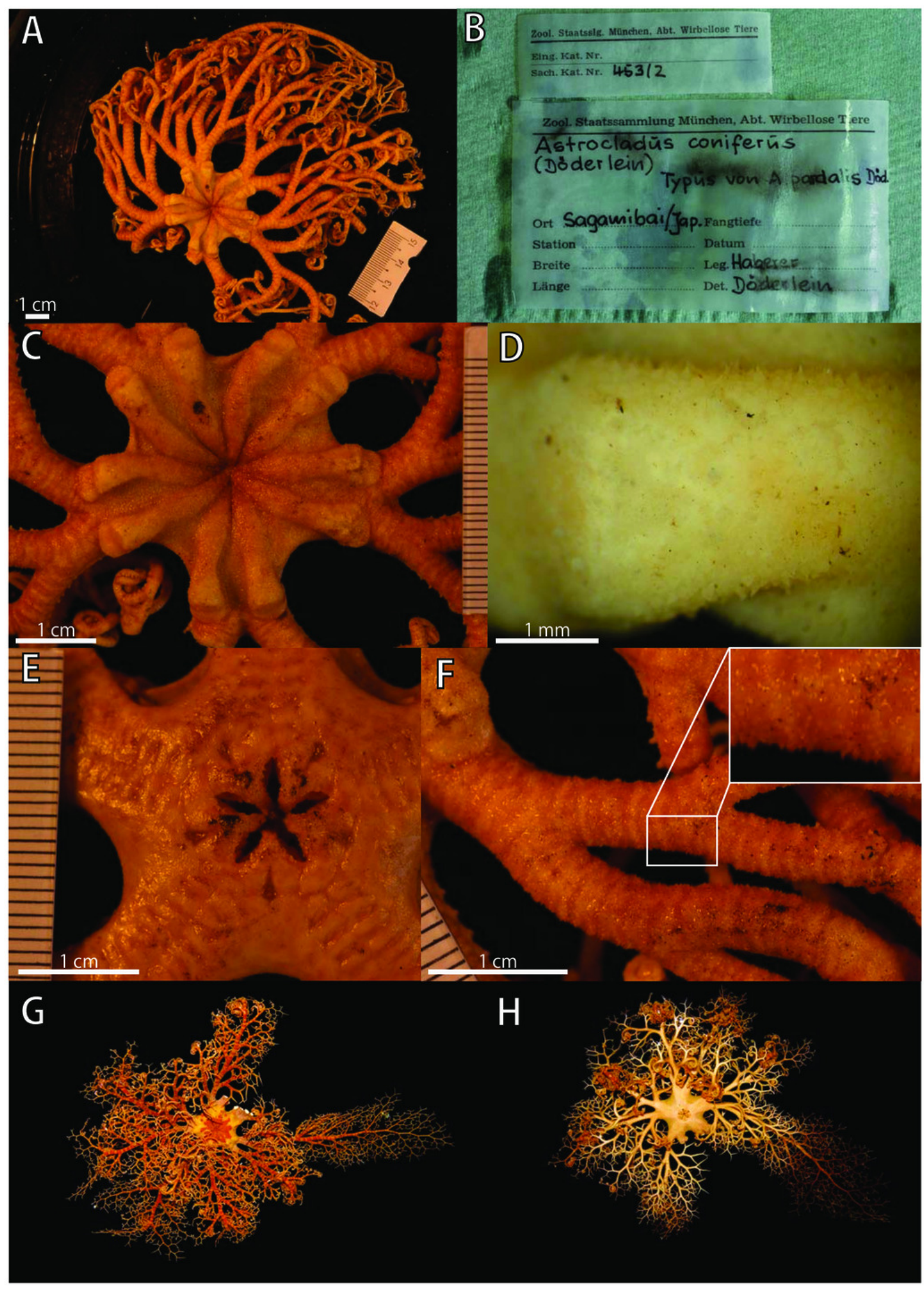




\section{Figure 5}

Figure 5. Astrocladus coniferus (MO-2018-118A). SEM photographs of ossicles.

(A-C) Hooklets on proximal (A), middle (B) and distal (C) portion of arm, arcs indicate reticular structure. (D) Hooket-bearing plate on proximal portion of arm. (E, F) Lateral arm plates on proximal portion of arm, internal (E) and external (F) views. (G, H) Arm spines from proximal portion of arm, inner most $(G)$ and second inner most $(H)$. (I, J) Lateral arm plates on middle portion of arm, distal (I) and internal (J) views. (K, L) Arm spines on middle portion of arms, inner most $(\mathrm{K})$ and second inner most (L). Arrowheads indicate articulations for hooklets (D) and terminal projections ( $G, H, K, L)$. Orientations: dis, distal side; ex, external side; in, internal side; prox, proximal side. Abbreviations: MO, muscle opening; NO, nerve opening; P, perforation; ST, secondary tooth. 


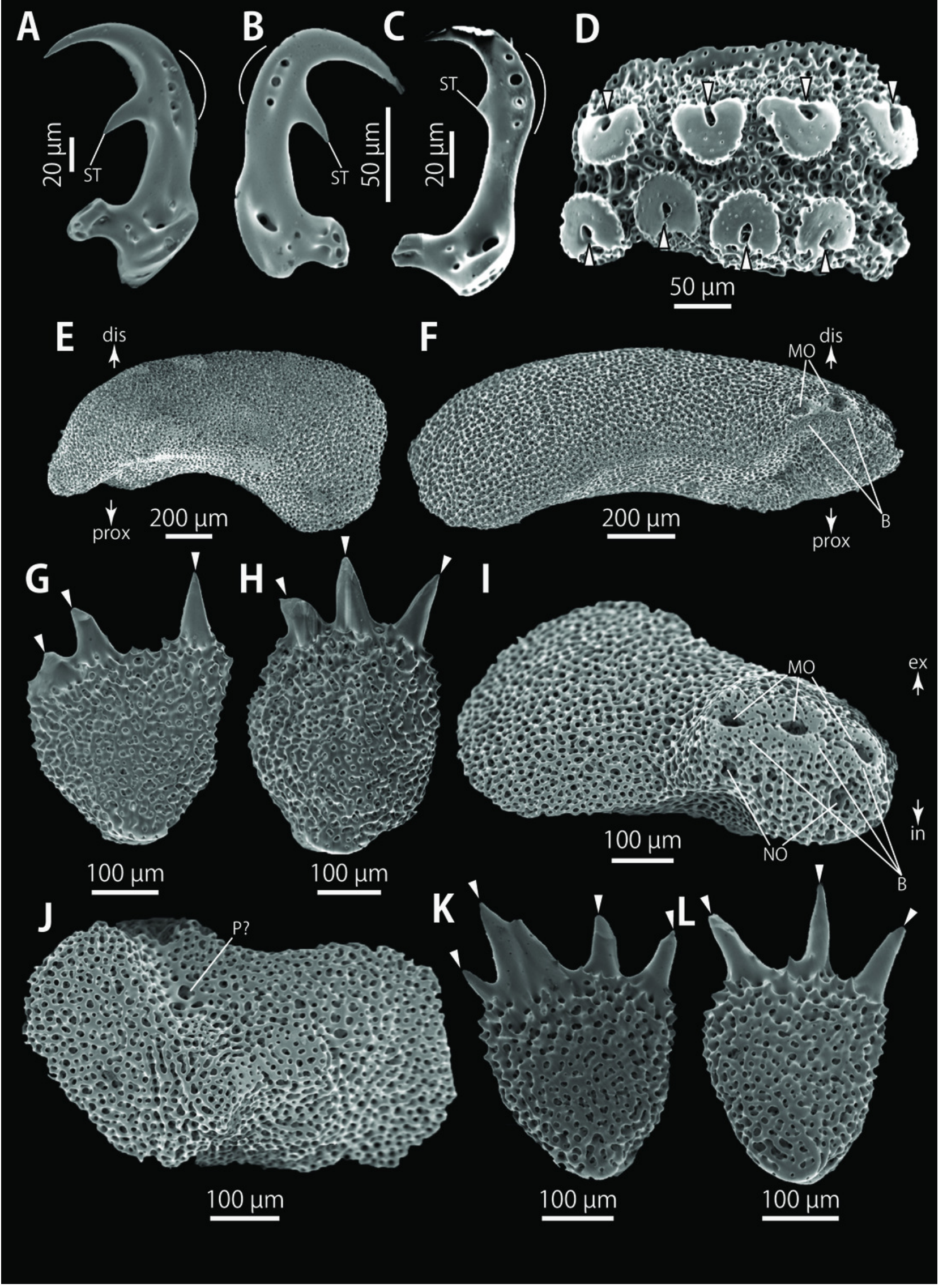




\section{Figure 6}

Figure 6. Astrocladus coniferus (NSMT E-13118). SEM photographs of ossicles.

(A, B) Lateral arm plates on distal portion of arm, external (A) and internal (B) views. (C) Hook-shaped arm spine on distal portion of arm. (D-G) Vertebrae from proximal (D, E) and middle $(F, G)$ portion of arm, distal $(D, G)$, ventral $(E)$ and proximal $(F)$ views. An arrowhead indicates articulation for hooklet (A). Abbreviations: AAS, articulation for arm spine; B, border structure; LN, passage of lateral canal; NO, nerve opening; ST, secondary tooth. 

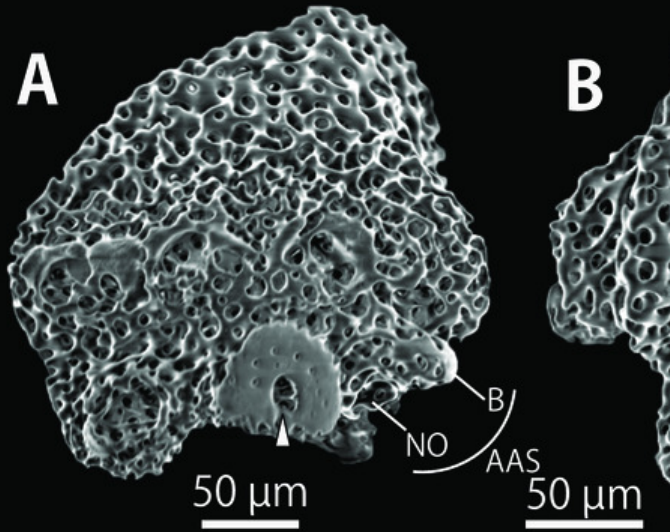

D

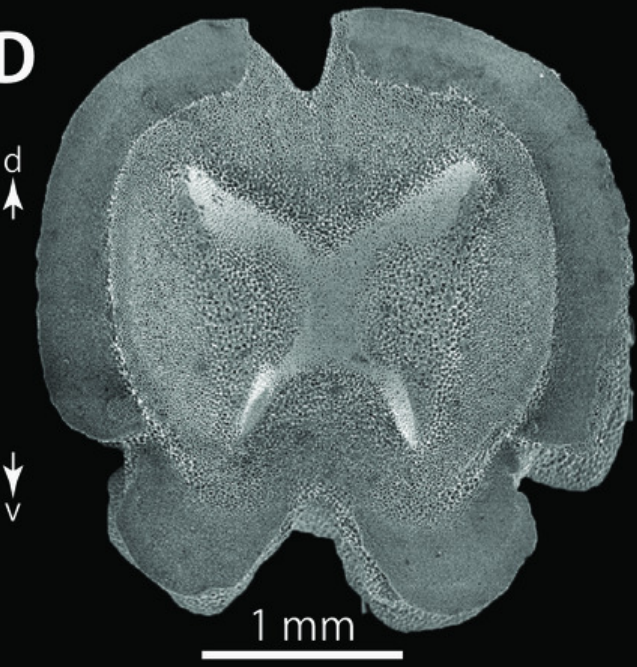

$\mathbf{F}$

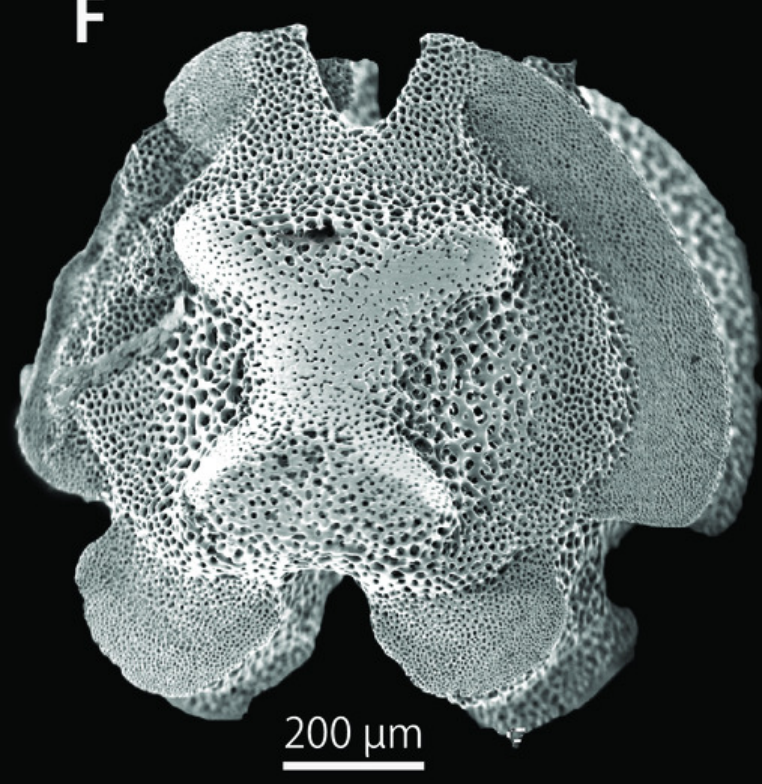

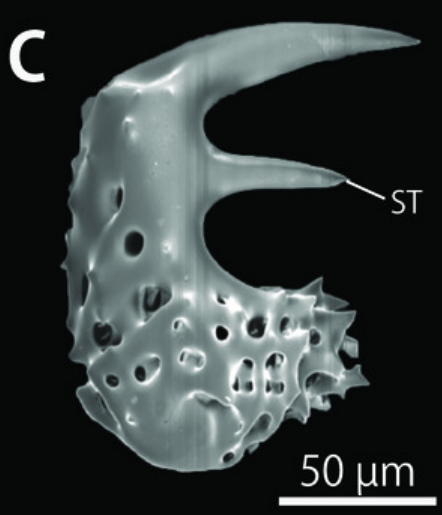

$50 \mu \mathrm{m}$

$$
\text { 13. }
$$
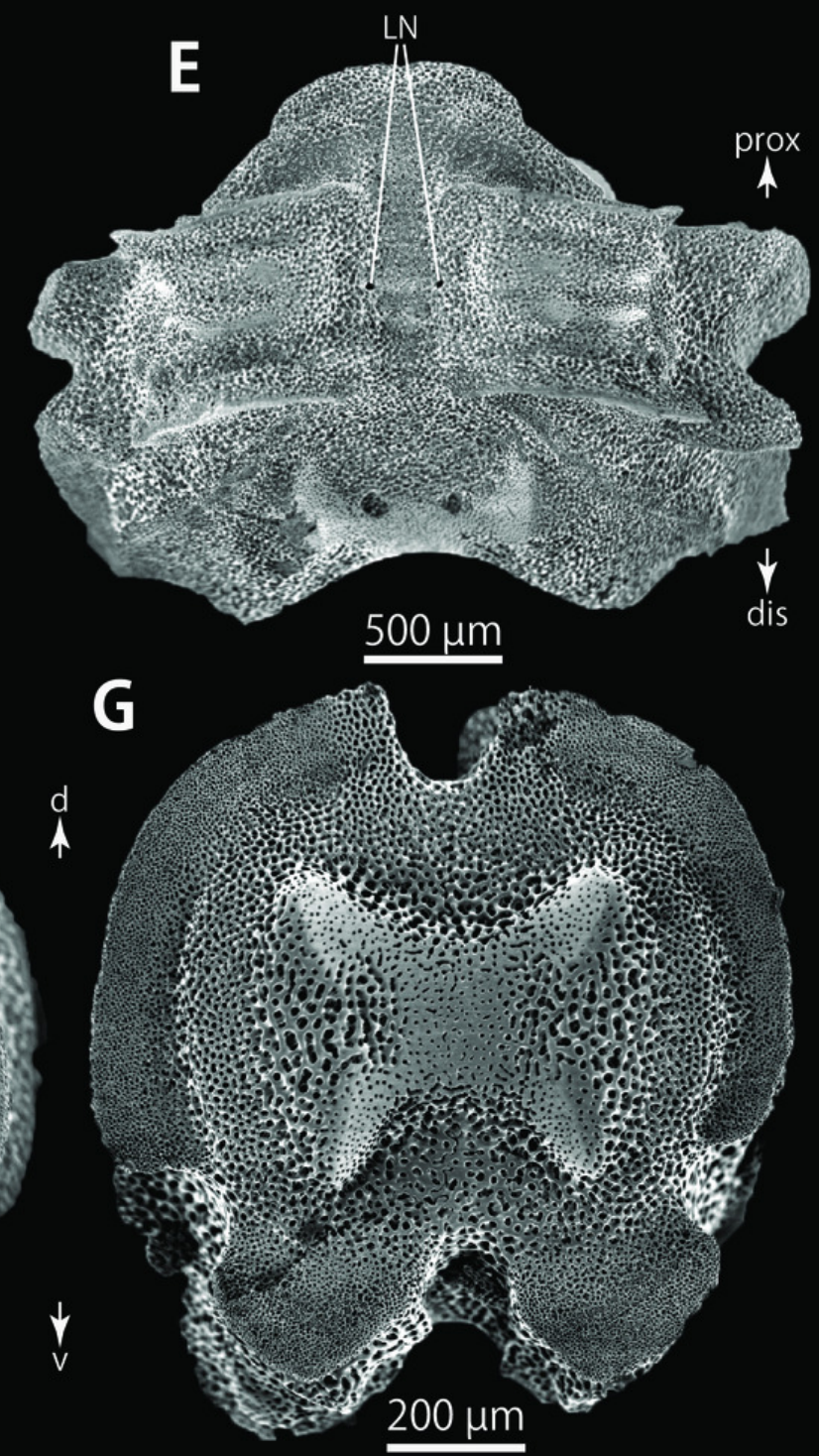


\section{Figure 7}

Figure 7. Astrocladus coniferus (MO-2018-118A). SEM photographs of ossicles.

Vertebrae from middle $(A, B)$ and distal $(C-F)$ portion of arm, ventral $(A, E)$, dorsal $(B, F)$, proximal (C) and distal (D) views. Orientations: $d$, dorsal side; dis, distal side; prox, proximal side; $v$, ventral side. Abbreviations: DT, depression for tentacle; LC, passages of lateral canal; $\mathrm{LN}$, passages of lateral nerve; $\mathrm{T}$, tubercle. 


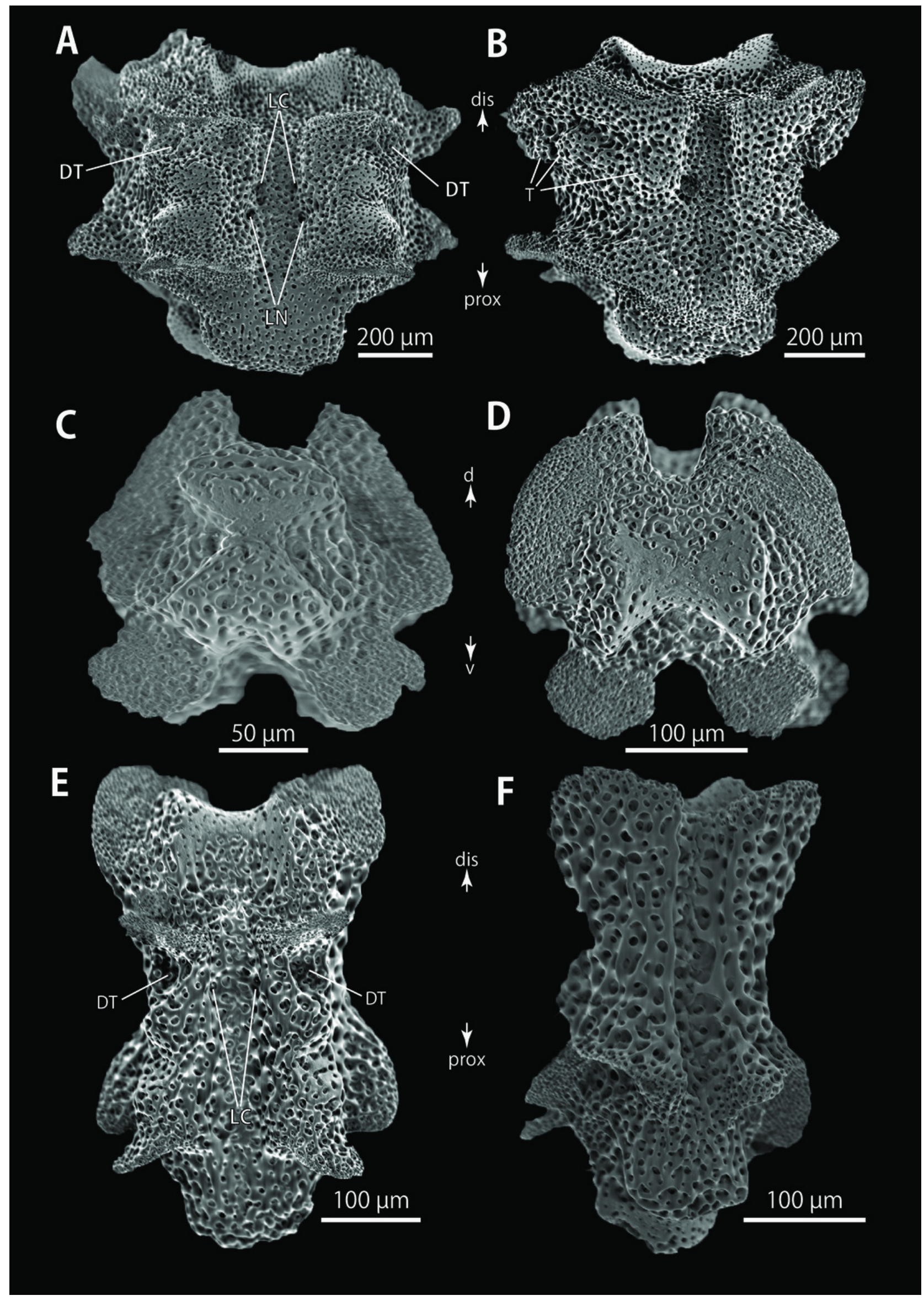




\section{Figure 8}

Figure 8. Astrocladus dofleini, lectotype (440/1).

(A) External view of lectotype bottle. (B) Labels of the lectotype. (C) Dorsal disc and proximal portion of arm. (D) Dorsal proximal portion of arm, partly enlarged in upper right. (E) Interradial ventral disc. (F) Dorsal middle to distal portion of arm. (G) Ventral disc and proximal portion of arm. (H) Ventral middle to distal tips of arm. Abbreviation: G, genital slit. 


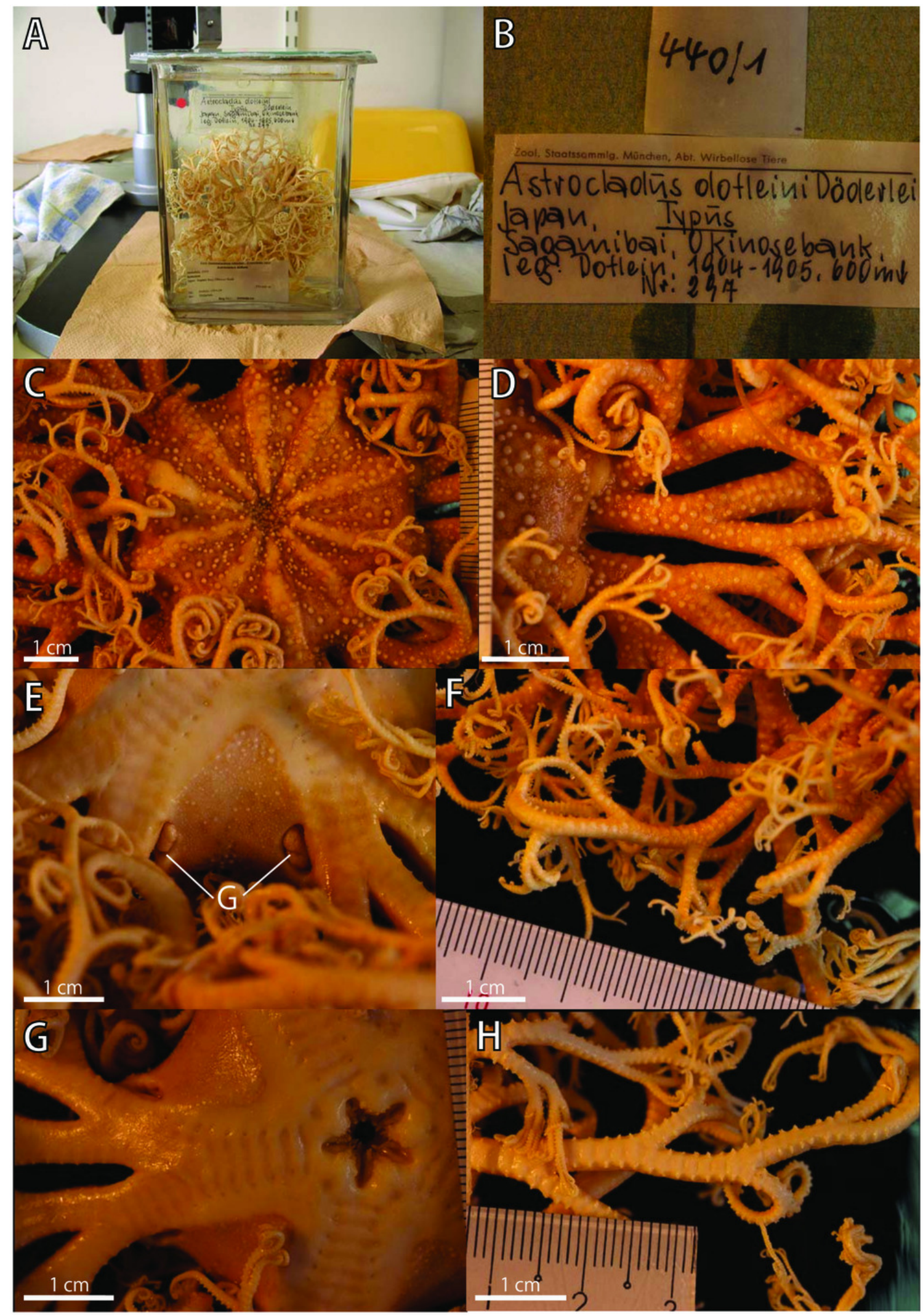




\section{Figure 9}

Figure 9. Astrocladus dofleini (NSMT E-13124). SEM photographs of ossicles.

(A, B, D) Hooklets on proximal (A), middle (B) and distal (D) portion of arms, arcs indicate reticular structure. (C, E) Hooket-bearing plate on proximal (C) and distal (E) portion of arm. (F, I) Arm spines on proximal (F) and middle (I) portion of arms. ( $G, H, J, K)$ Lateral arm plates on proximal $(G, H)$ and middle $(J, K)$ portion of the arms, external $(G, J)$ and internal $(H, K)$ views. Arrowheads indicate articulations of hooklets $(C, E, J)$ and terminal projections $(F)$. Orientations: d, dorsal side; dis, distal side; ex, external side; in, internal side prox, proximal side; $v$, ventral side. Abbreviations: AAS, articulation for arm spine; B, border structure; MO, muscle opening; NO, nerve opening; ST, secondary tooth. 


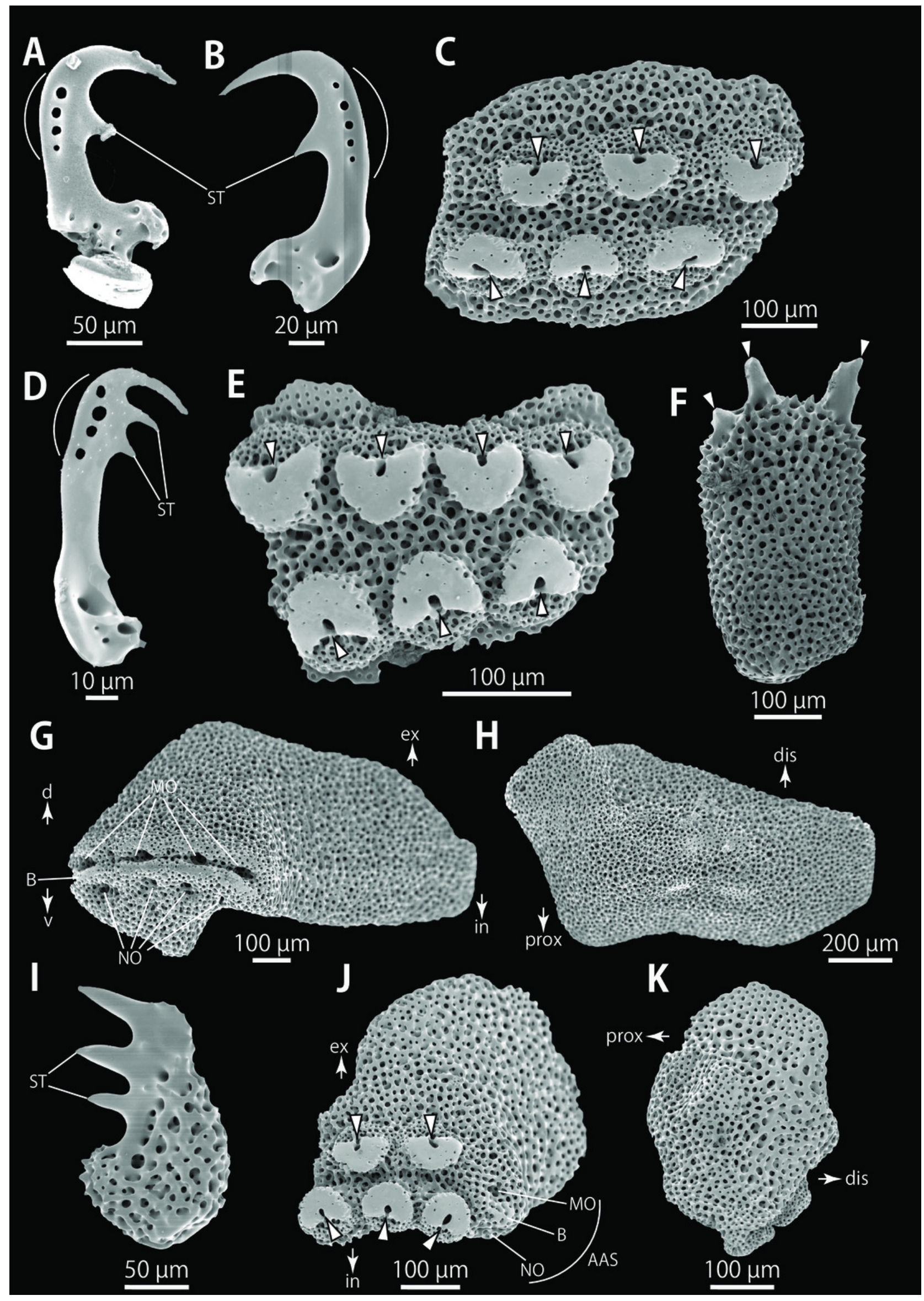

Peer) reviewing PDF | (2020:05:49200:1:2:CHECK 31 Jul 2020) 


\section{Figure 10}

Figure 10. Astrocladus dofleini (NSMT E-13124). SEM photographs of ossicles.

(A) An arm spine from distal portion of arm. (B, C) Lateral arm plates on distal portion of arm, external (B) and internal (C) views. (D-H) Vertebrae from proximal portion of arm (H is branching vertebra), distal $(D)$, proximal $(E)$, dorsal $(F)$ and ventral $(G, H)$ views. Orientations: $d$, dorsal side; dis, distal side; prox, proximal side; $v$, ventral side. Arrowheads indicate articulations for hooklets. Abbreviations: B, boarder structure; DT, depression for tentacle; LC, passages of lateral canal; LN, passages of lateral nerve; MO, muscle opening; ST, secondary tooth; T, tubercle. 

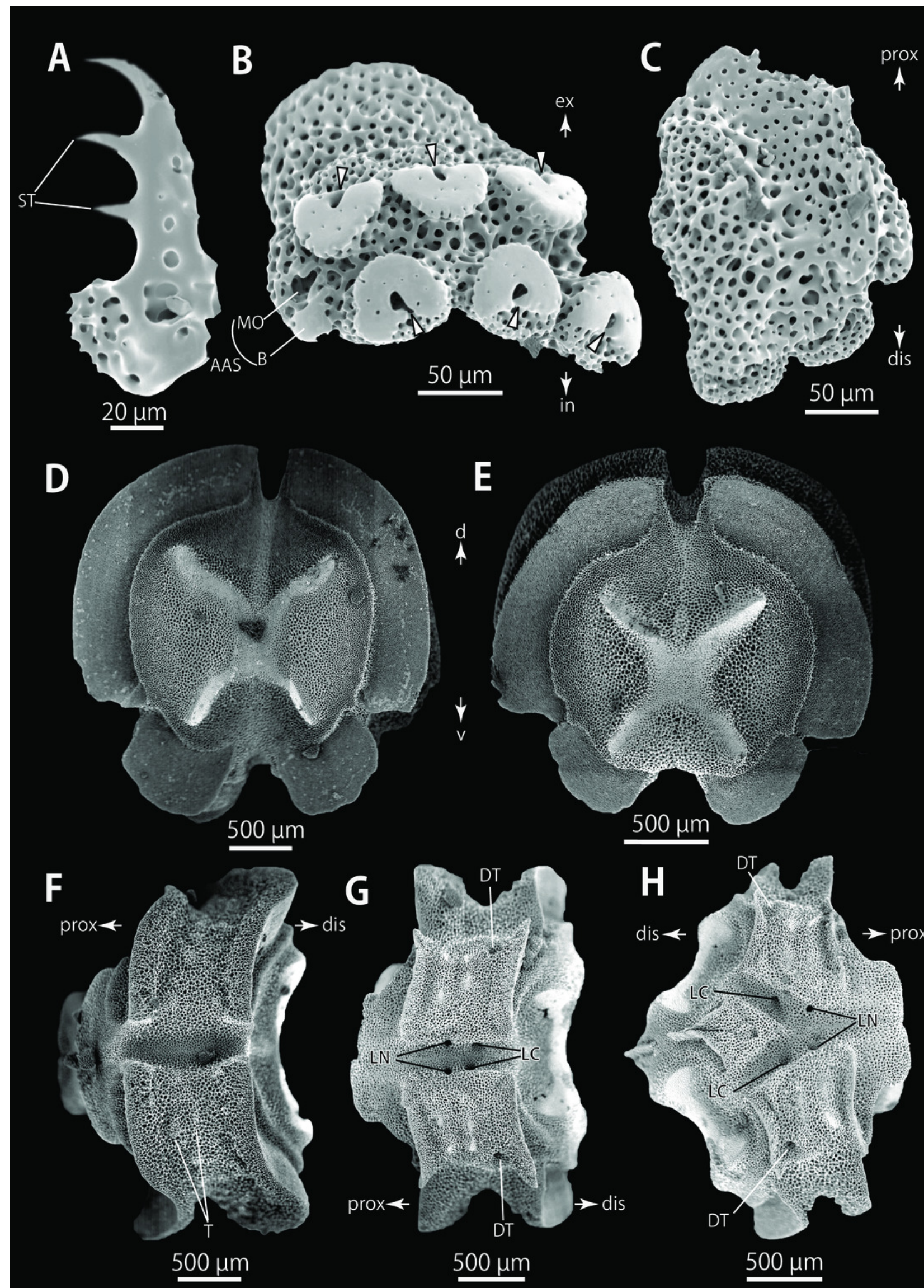


\section{Figure 11}

Figure 11. Astrocladus dofleini (MO-2018-118B). SEM photographs of ossicles.

(A-E) Vertebrae from middle portion of arm ( $C$ is branching vertebra), distal ( $A$ ), ventral ( $B$, $C)$, dorsal (D) views, a part of (D) enlarged in (E). Vertebrae from distal portion of arm $(F, G)$, distal (F) and proximal (G)views. Orientations: $d$, dorsal side; dis, distal side; prox, proximal side; $v$, ventral side. Arrowheads indicate tubercles on lateral furrow of vertebra. Abbreviations: DT, depression for tentacle; LC, passages of lateral canal; LN, passages of lateral nerve; T, tubercle. 


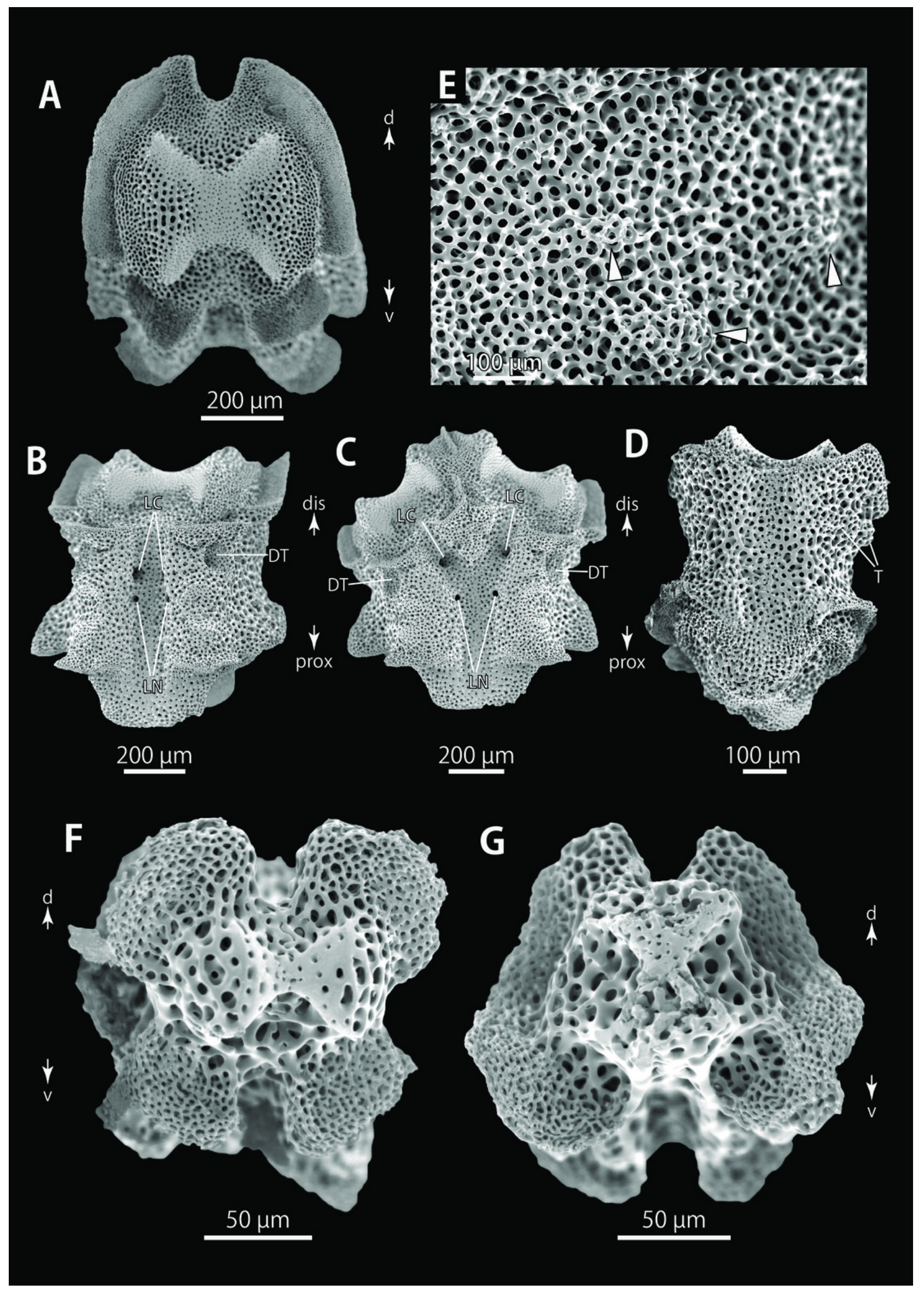




\section{Figure 12}

Figure 12. Astrocladus dofleini (MO-2018-118B).

SEM photographs of vertebrae from distal portion of arm ( $\mathrm{C}$ is branching vertebra), ventral $(A, C)$ and dorsal (B) views. Orientations: dis, distal side; prox, proximal side. Abbreviation: DT, depression for tentacle. 


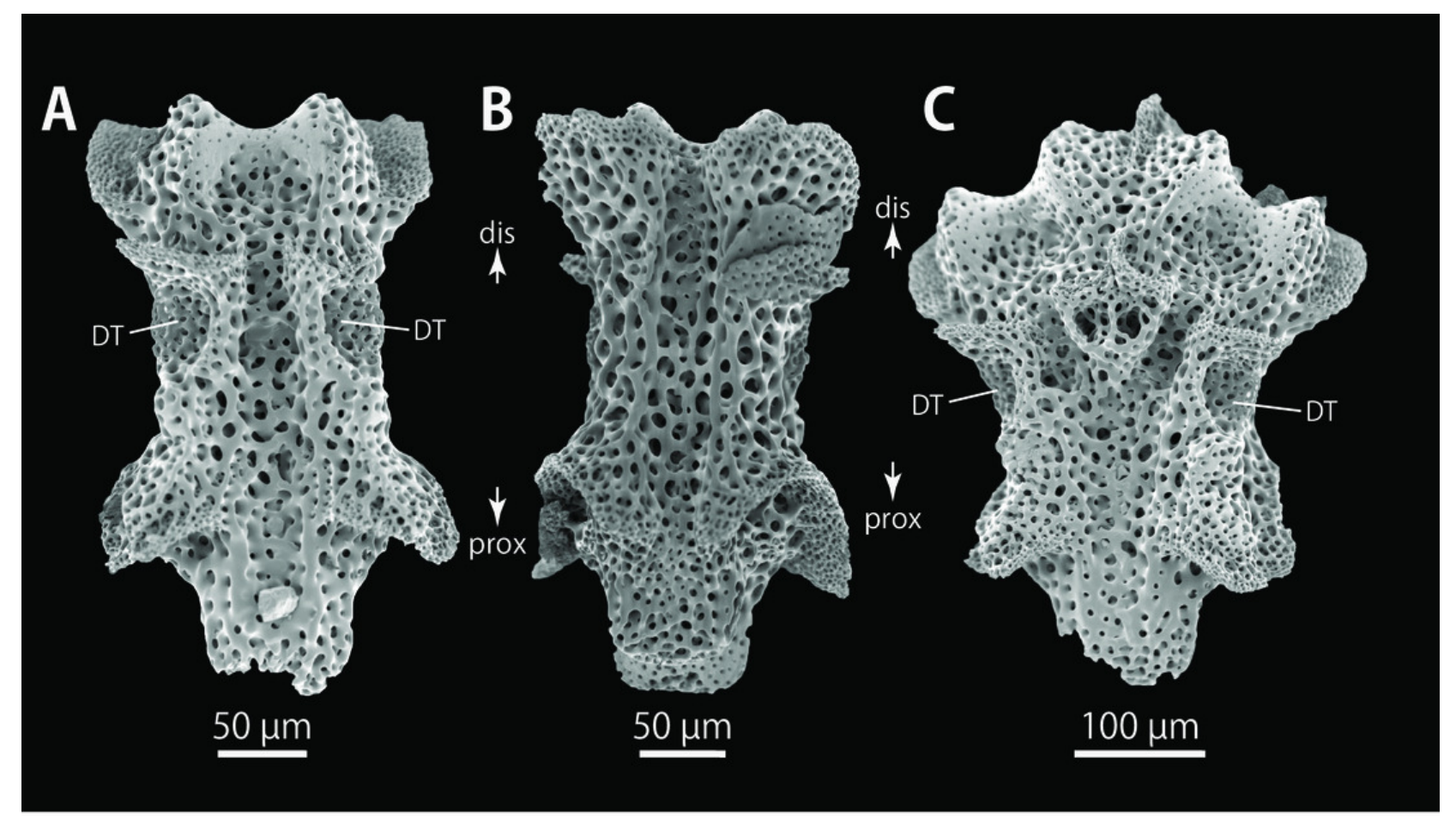




\section{Figure 13}

Figure 13. Astrocladus exiguus (MO-2019-19).

(A) Periphery of dorsal disc. (B) Central view of dorsal disc. (C) Ventral disc. (D) Interradial ventral disc. (E-G) Ventral surfaces of arms, proximal $(E)$, middle $(F)$ and distal $(G)$ portion of arm. Dorsal surfaces of arms, proximal (H), middle (I) and distal (J) portion of arm. Arrowheads indicate rows of hooklets on dorsal and lateral side of the arms $(\mathrm{I}, \mathrm{J})$. Abbreviations: AS, arm spine; G, genital slit; M, madreporite; $T$, large tubercle. Photographs of this figure were focus-stacked using the software CombineZM v. 1.0.0 ( https://www.softpedia.com/get/Multimedia/Graphic/Graphic-Editors/CombineZM.shtml ). 


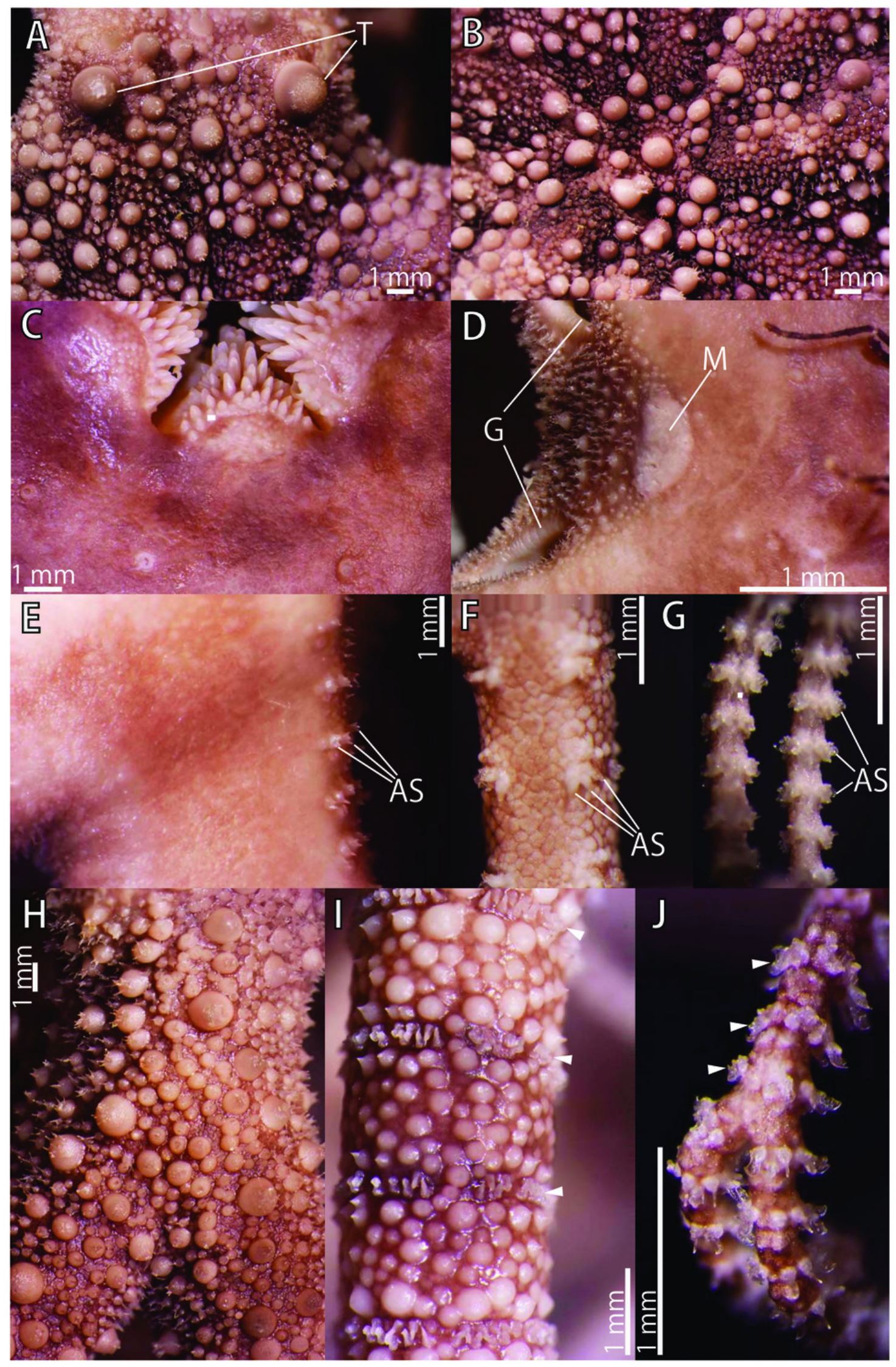




\section{Figure 14}

Figure 14. Astrocladus exiguus (NSMT E-13126). SEM photographs of ossicles.

(A, C) Hooklets on proximal (A) and distal (C) portion of arms, arcs indicate reticular

structure. (B, D) Hooket-bearing plate on proximal (B) and distal (D) portion of arm. $(E-H)$ Lateral arm plates on proximal $(E, F)$ and distal $(G, H)$ portion of arms. (I) An arm spine on proximal portion of arm. Arrowheads indicate articulations for hooklets $(B, D, H)$ and terminal projections (I). Orientations: $d$, dorsal side; dis, distal side; ex, internal side; in, internal side; prox, proximal side; $v$, ventral side. Abbreviations: AAS, articulation for arm spine; $B$, border structure; MO, muscle opening; NO, nerve opening; ST, secondary tooth. 

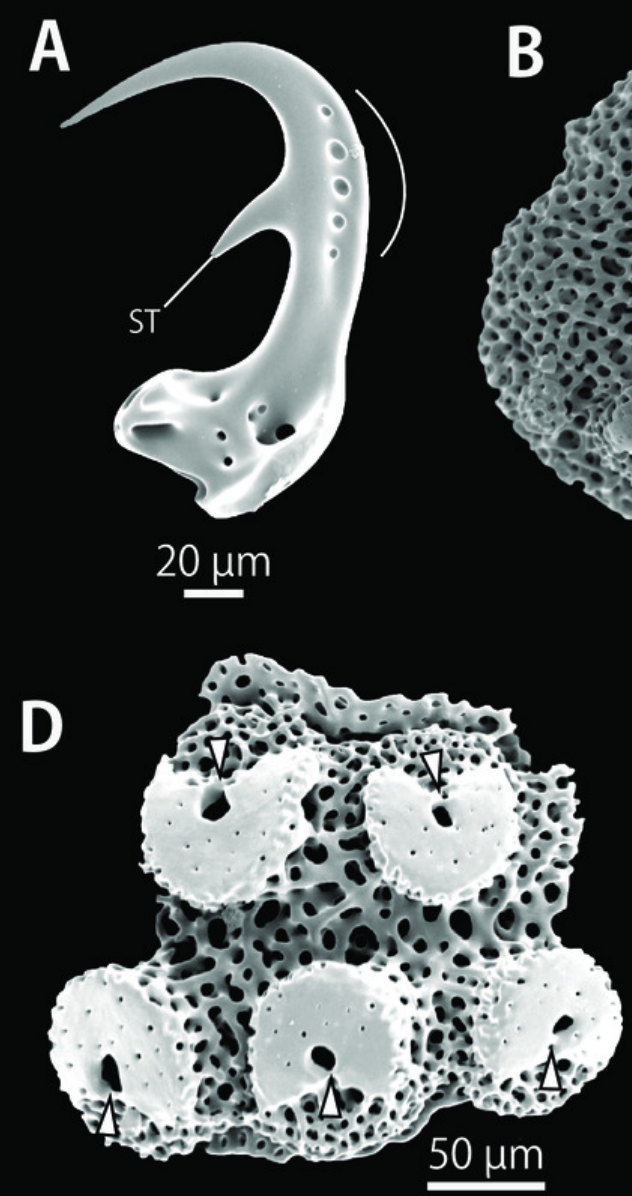

$\mathbf{F}$

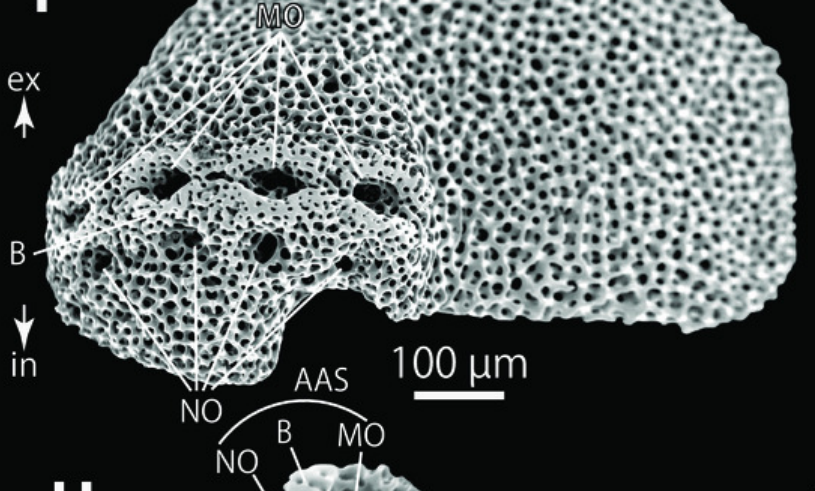

H

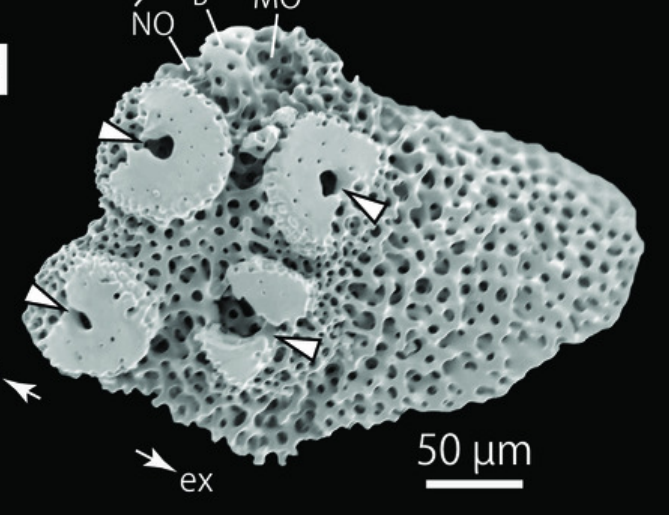

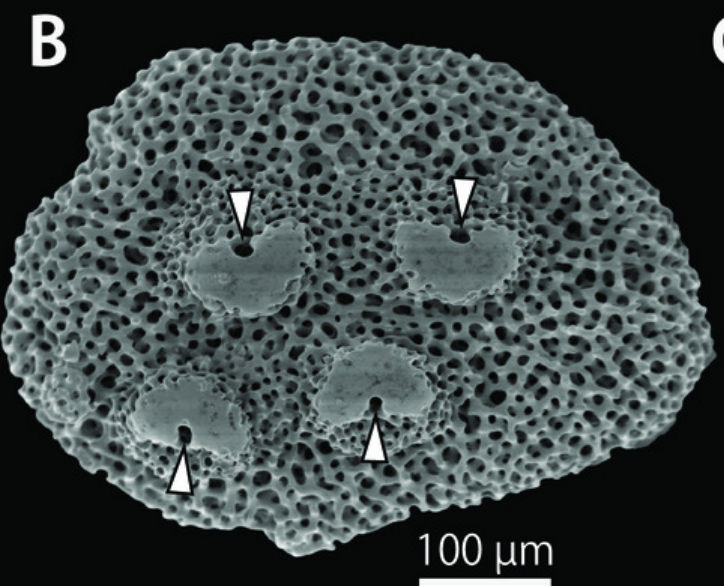

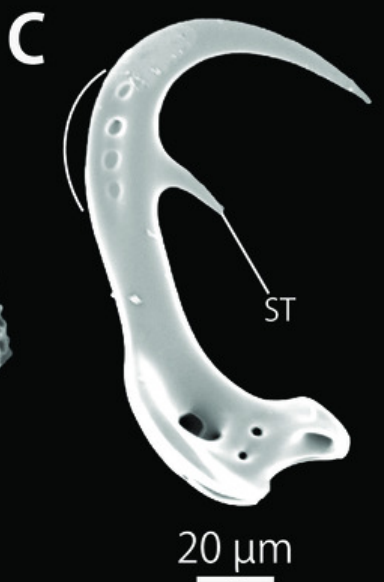

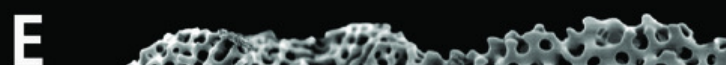

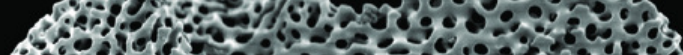

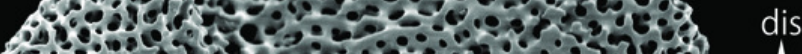

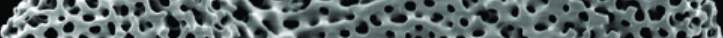
Aly

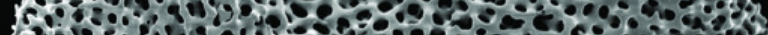

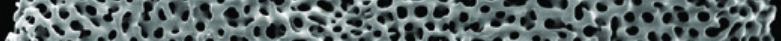

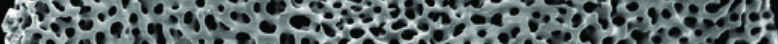

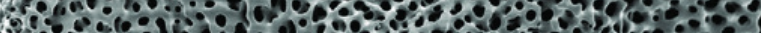

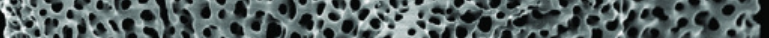

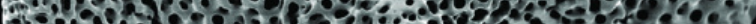
\%

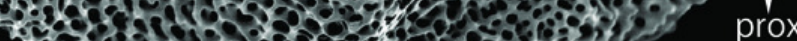
EC $x 20$. $100 \mu \mathrm{m}$

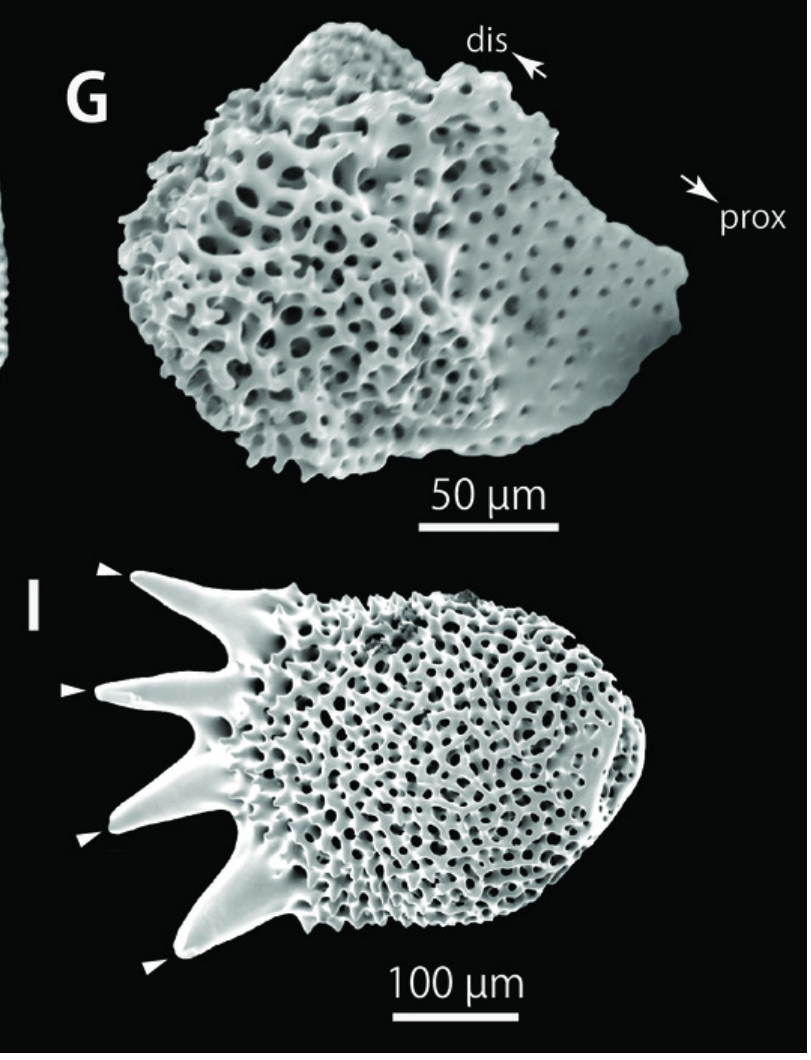

Peer) reviewing PDF | (2020:05:49200:1:2:CHECK 31 Jul 2020) 


\section{Figure 15}

Figure 15. Astrocladus exiguus (MO-2019-19). SEM photographs of ossicles.

(A) An arm spine on distal portion of arm. (B-F) Vertebrae from proximal portion of arm (E is branching vertebra), proximal $(B)$, distal $(C)$, ventral $(D, E)$ and dorsal $(F)$ views. $(G, H)$ Vertebrae from distal portion of arm, proximal $(G)$ and distal $(H)$ views. Orientations: $d$, dorsal side; dis, distal side; prox, proximal side; v, ventral side. Abbreviations: DT, depression for tentacle; LC, passages of lateral canal; LN, passages of lateral nerve; ST, secondary tooth. 


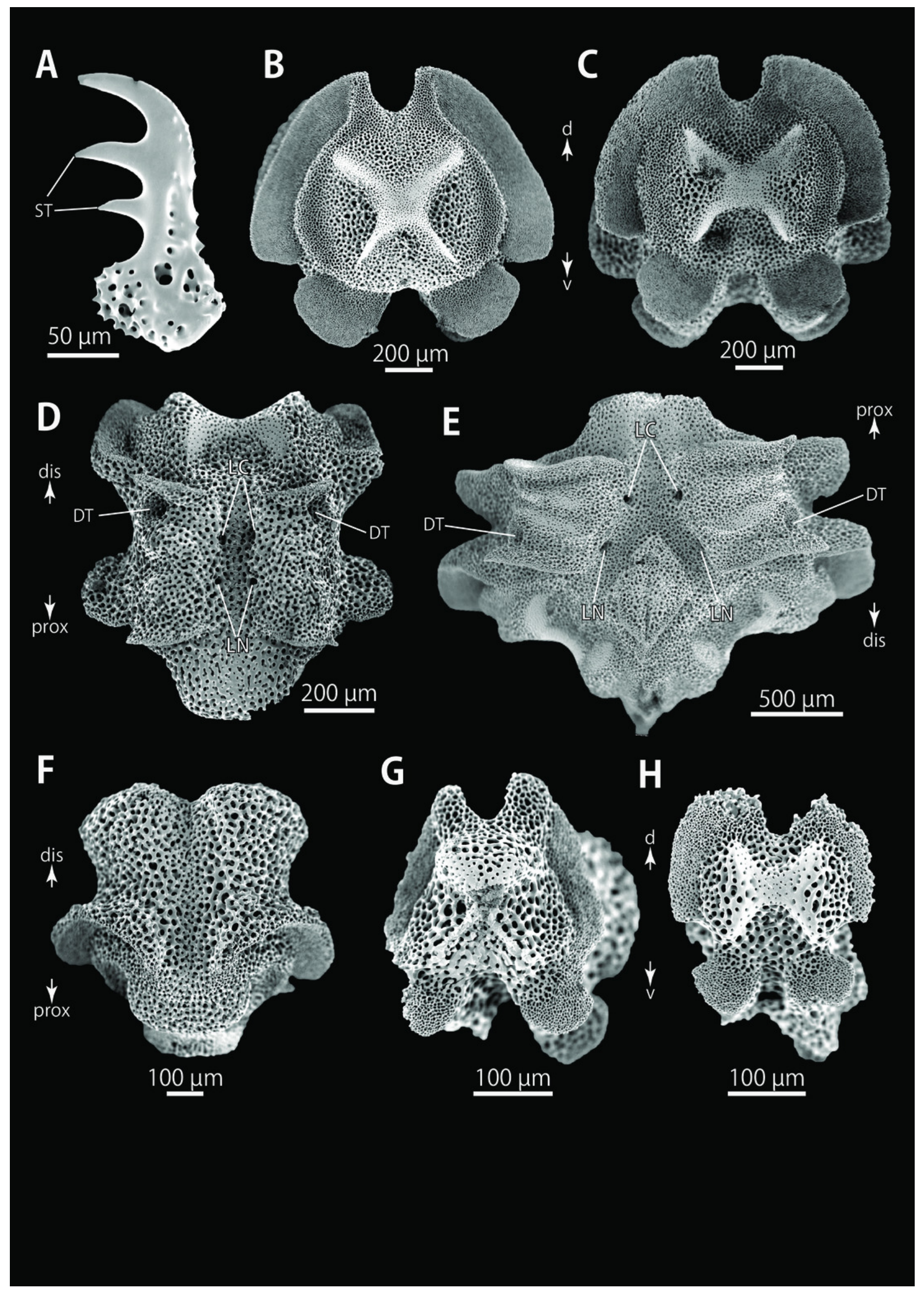




\section{Figure 16}

Figure 16. Astrocladus exiguus (MO-2019-19). SEM photographs of ossicles.

$(A-C)$ Vertebrae from distal portion of arm (B is branching vertebra), dorsal $(A)$, ventral $(B, C)$ views. (D) An conical external ossicle on proximal portion of arm, lateral view, an arc indicates a terminal projection. Orientations: ba, basal side; dis, distal side; ex, external side; prox, proximal side. Abbreviations: DT, depression for tentacle; LC, passages for lateral canals. 
A

(2)

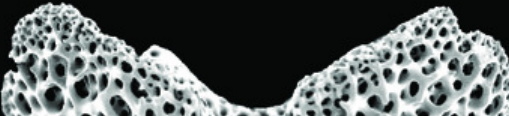
Go

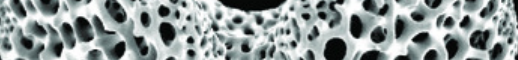

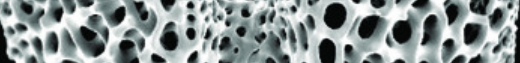

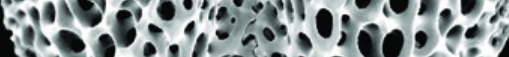

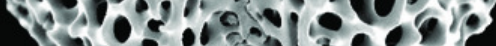
C)

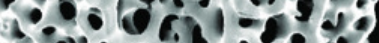

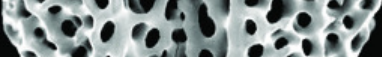

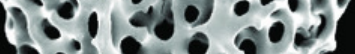
10.920 .5 (6) हैं हैं

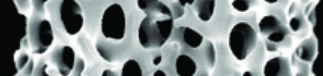
$30=0 ; 9.087$

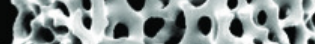
$1006 \cdot 5.90 .95$ ser l

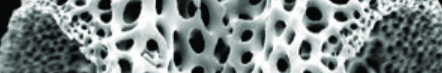
$20=1030: 50$ ? L 38 .

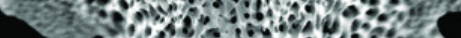

- 460 5. 13\%:080.5 $\because \because \because \frac{1}{3}$,

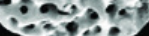
$100 \mu \mathrm{m}$

C

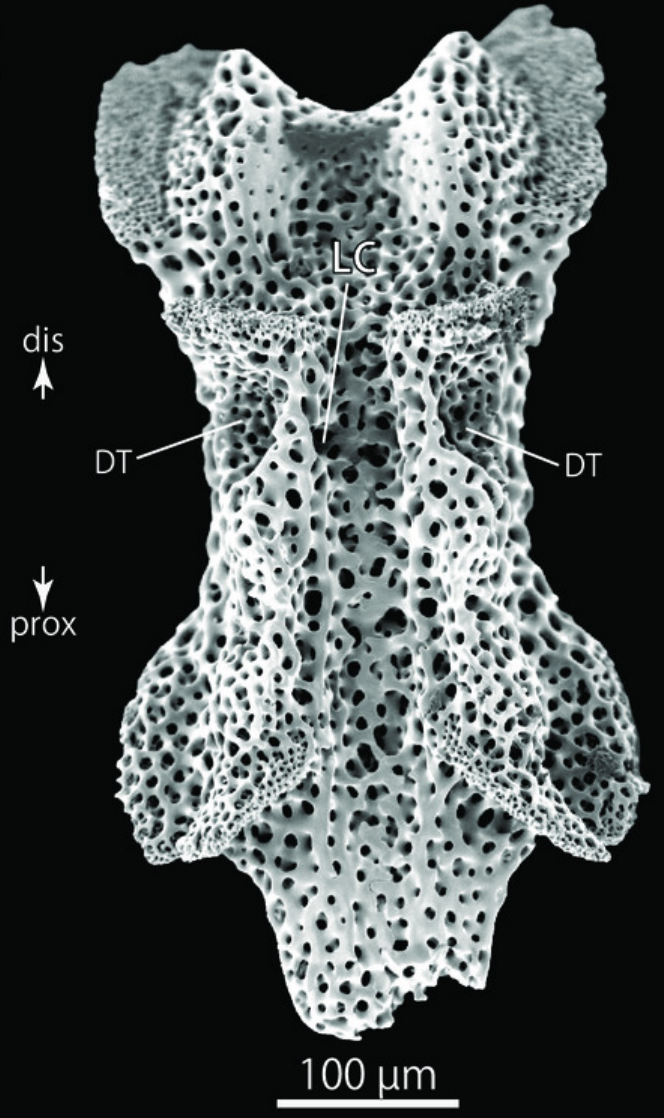

D

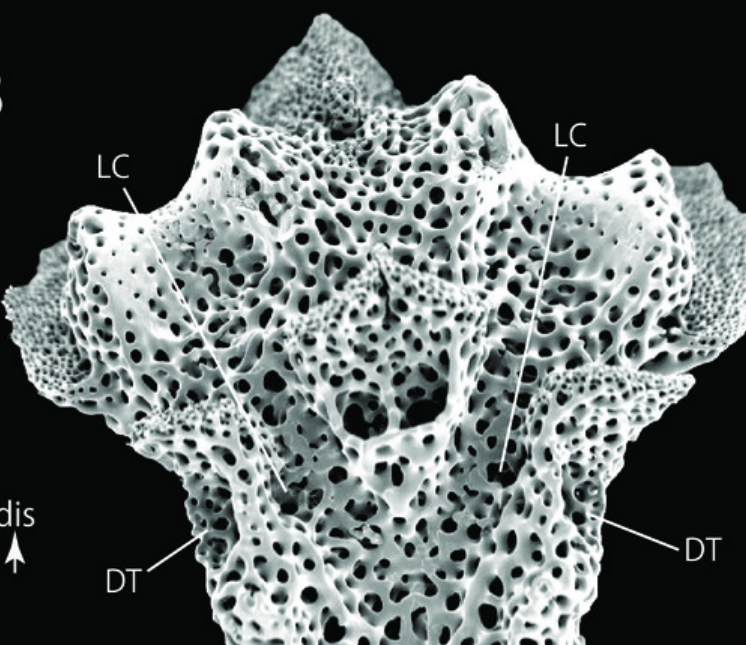

$3-1000.00=$

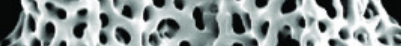

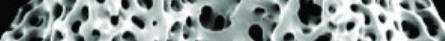

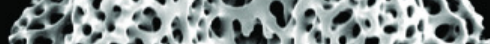

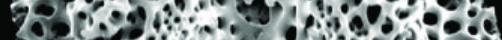

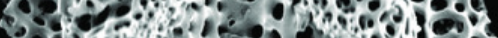
?

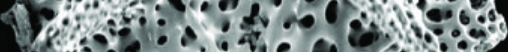
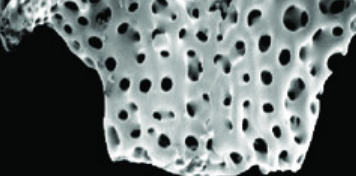

D

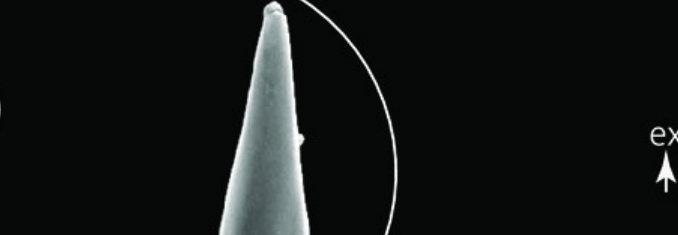
$\uparrow$ 


\section{Figure 17}

Figure 17. Astrocladus annulatus, holotype (UMUTZ-Ophi-26).

(A) Dorsal view. (B) Dorsal surface of periphery disc (C) Ventral view. (D) Jaws. (E) Interradial ventral disc. (F-H) Dorsal surface of arms, proximal $(F)$, middle $(G)$ and distal $(H)$ portion of arm. (I, J) Ventral surface of arms, proximal (I) and distal (J) portion of arm. Arrowheads indicate rows of hooklets on dorsal and lateral side of the arms (B, G, H). Abbreviations: AS, arm spine; G, genital slit. 

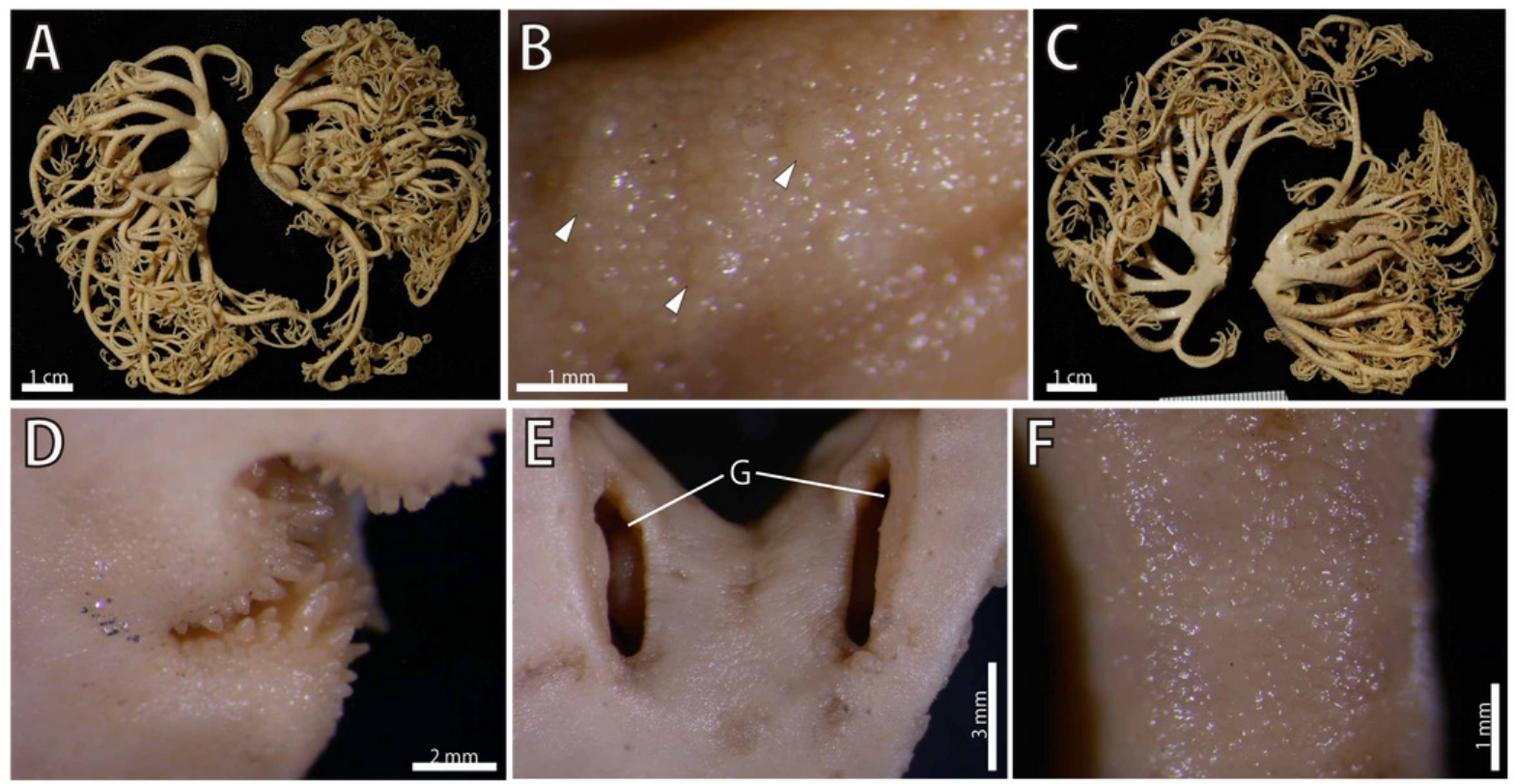

F
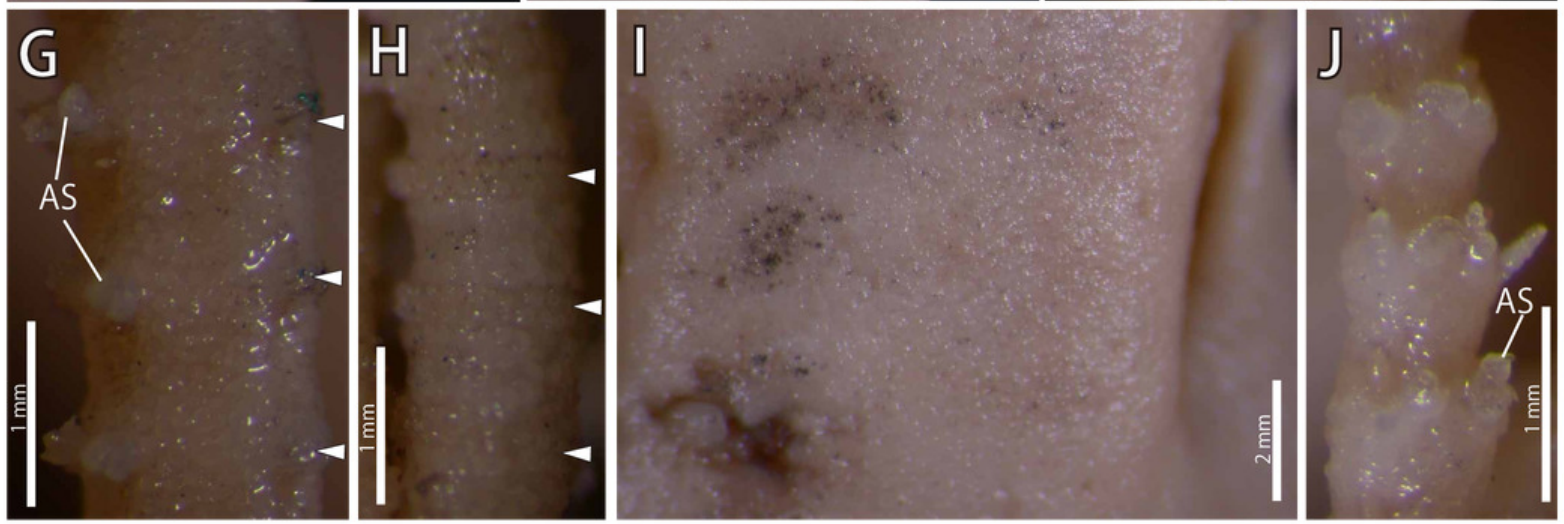


\section{Figure 18}

Figure 18. Maximum likelihood tree based on a partial sequence of mitochondrial COI gene (699 bp).

Support values for each node are shown by maximum likelihood bootstrap values (\%) and Bayesian posterior probabilities. Numerals (1-5) in circles at nodes refer to the clade number discussed in the text. Bootstrap value less than $74 \%$ and Bayesian posterior probability value less than 0.97 and for each node were shown by as "-".

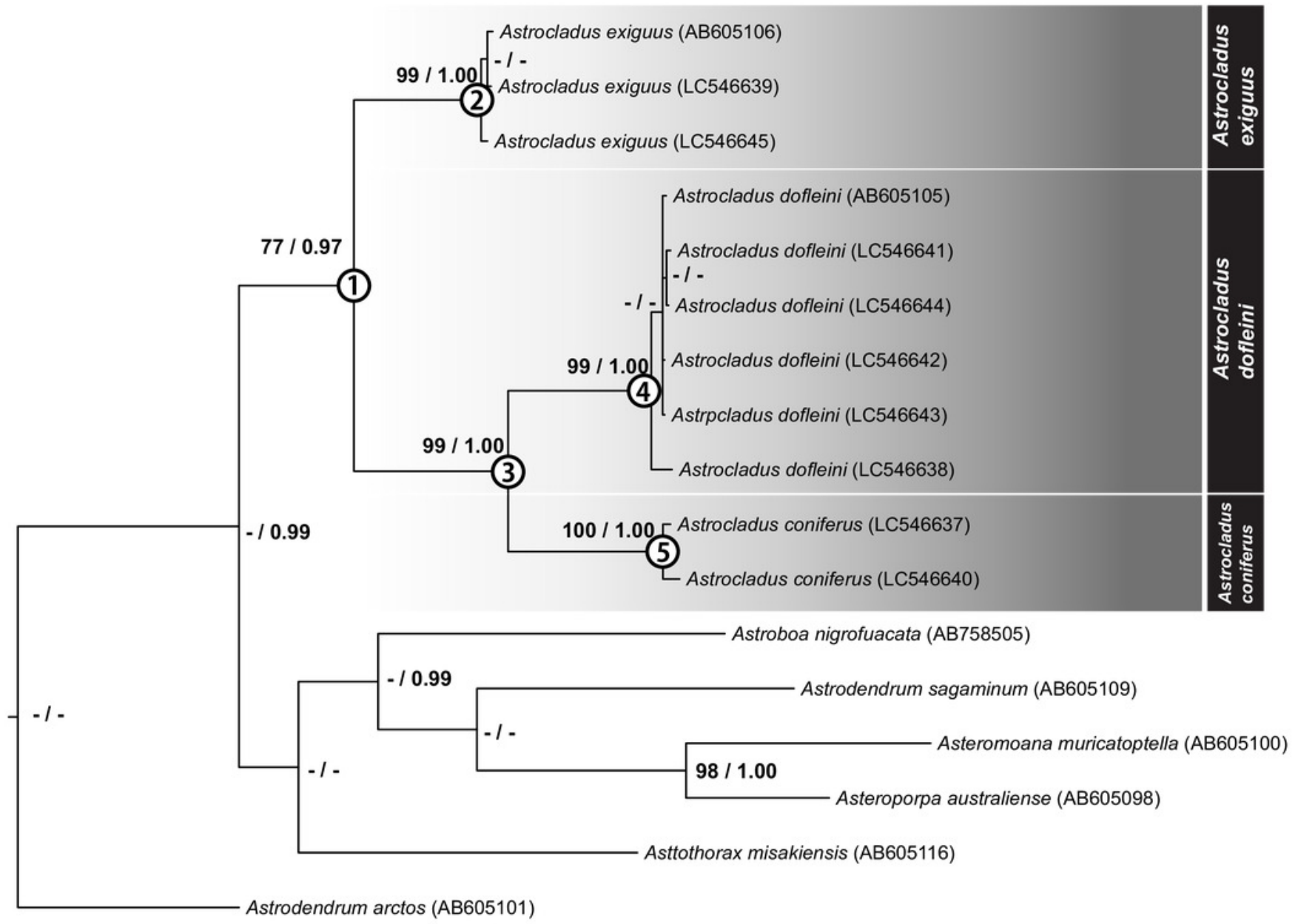




\section{Table $\mathbf{1}$ (on next page)}

Table 1: Examined specimens of Astrocladus species including outgroup.

$\mathrm{COI}$ accession numbers are lodged at the DNA Data Bank of Japan. See referees for the detailed information. Unknown data are shown by "-". Abbreviations: NSMT, the National Museum of Nature and Science, Tsukuba, Japan; UMUT, The University Museum, The University of Tokyo, Japan; ZMB, Museum für Naturkunde der Humboldt-Universität zu Berlin, Germany; ZSM, the Zoologische Staatssammlung München, Germany. 


\begin{tabular}{|c|c|c|c|c|c|c|c|c|}
\hline $\begin{array}{l}\text { Specimen } \\
\text { No. }\end{array}$ & Species & Catalogue. number & Locality & $\begin{array}{l}\text { Depth } \\
\text { (m) }\end{array}$ & $\begin{array}{l}\text { Date of } \\
\text { sampling }\end{array}$ & Type status & $\begin{array}{l}\text { COI } \\
\text { Access. no. }\end{array}$ & References \\
\hline 1 & Astrocladus annulatus & UNUTZ-Ooh-26 & Off Misaki, Sagami Bay, Kanagawa & - & - & Holotype & - & Matsumoto, 1912 \\
\hline 2 & Astrocladus coniferus & NSMT E-13118 & $\begin{array}{l}\text { Sagami Bay, Hama Moroiso, Koajiro, } \\
\text { Kanagawa, Japan }\end{array}$ & $0.5-1.0$ & $2018 / 3 / 12$ & Non type & LC546637 & This study \\
\hline 3 & Astrocladus coniferus & NSMT E-13119 & $\begin{array}{l}\text { Hashiraguri, Oki Island, Dohgo, } \\
\text { Shimane, Japan }\end{array}$ & ca. 20 & $2010 / 7 / 15$ & Non type & LC546640 & This study \\
\hline 4 & Astrocladus coniferus & ZSM 453/1 & Kagoshima Bay, Kagoshima & ca. 30 & $1880 / 8$ & Lectotype & -- & Döderlein, 1902 \\
\hline 5 & Astrocladus pardaris & ZSM 453/2 & Sagami Bay, Kanagawa & - & - & Holotype & -- & Döderlein, 1902 \\
\hline 6 & Astrocladus dofleini & NSMT E-13120 & $\begin{array}{l}\text { Tachibana Bay, Off Mogi, Nagasaki, } \\
\text { Japan }\end{array}$ & ca. 40 & $2019 / 2 / 7$ & Non type & LC546641 & This study \\
\hline 7 & Astrocladus dofleini & NSMT E-13121 & $\begin{array}{l}\text { Tachibana Bay, Off Mogi, Nagasaki, } \\
\text { Japan }\end{array}$ & ca. 40 & $2019 / 2 / 7$ & Non type & LC546642 & This study \\
\hline 8 & Astrocladus dofleini & NSMT E-13122 & $\begin{array}{l}\text { Tachibana Bay, Off Mogi, Nagasaki, } \\
\text { Japan }\end{array}$ & ca. 40 & $2019 / 2 / 7$ & Non type & LC546643 & This study \\
\hline 9 & Astrocladus dofleini & NSMT E-13123 & $\begin{array}{l}\text { Tachibana Bay, Off Mogi, Nagasaki, } \\
\text { Japan }\end{array}$ & ca. 40 & $2019 / 2 / 7$ & Non type & LC546644 & This study \\
\hline 10 & Astrocladus dofleini & NSMT E-5480 & Off Minabe, Wakayama & ca. 80 & $2006 / 3 / 10$ & Non type & AB605105 & Okanishi \& Fujita, 2013 \\
\hline 11 & Astrocladus dofleini & NSMT E-10749 & Off Kuji, Hitachi, Ibaraki & - & $2016 / 9 / 30$ & Non type & LC546638 & This study \\
\hline 12 & Astrocladus dofleini & NSMT E-13124 & $\begin{array}{l}\text { Sagami Bay, Mouthe of Koajiro Bay, } \\
\text { Kanagawa, Japan }\end{array}$ & 15 & $2018 / 6 / 6$ & Non type & - & This study \\
\hline 13 & Astrocladus dofleini & ZSM 440/1 & Okinose, Sagami Bay, Kanagawa & 600 & $1904-1905$ & Lectotype & - & Döderlein, 1910 \\
\hline 14 & Astrocladus dofleini & ZSM 440/1 & Okinose, Sagami Bay, Kanagawa & 600 & 1904-1905 & Paralectotype & - & Döderlein, 1910 \\
\hline 15 & Astrocladus exiguus & NSMT E-6265 & Off Yaku-shima Island, Kagoshima & $155-170$ & $2008 / 8 / 2$ & Non type & AB605106 & Okanishi \& Fujita, 2013 \\
\hline 16 & Astrocladus exiguus & NSMT E-13125 & Off Minabe, Wakayama & - & $2012 / 11 / 22$ & Non type & LC546639 & This study \\
\hline
\end{tabular}




\begin{tabular}{|c|c|c|c|c|c|c|c|c|}
\hline 17 & Astrocladus exiguus & NSMT E-13126 & Off Minabe, Wakayama & - & $2019 / 4 / 4$ & Non type & LC546645 & This study \\
\hline 18 & Asteromoana muricatopatella & NSMT E-5619B & Off Yaku-shima Isl., Kagoshima. & 140 & $2007 / 9 / 26$ & Non type & AB605100 & Okanishi \& Fujita, 2013 \\
\hline 19 & Asteroporpa australiense & MV F99691 & Wanganella Bank, New Zealand. & $254-259$ & $2003 / 5 / 28$ & Non type & AB605098 & Okanishi \& Fujita, 2013 \\
\hline 20 & Astroboa arctos & NSMT E-6718 & Off Minabe, Wakayama & ca. 30 & $2009 / 2 / 26$ & Non type & AB605101 & Okanishi \& Fujita, 2013 \\
\hline \multirow[t]{2}{*}{21} & Astroboa nigrofurcata & MNHN IE-2013- & Northern Pacific & $143-173$ & $1998 / 8 / 7$ & Non type & $\mathrm{AB} 758505$ & Okanishi \& Fujita, 2013 \\
\hline & & 8003 & & & & & & \\
\hline 22 & Astrodendrum sagaminum & NSMT E-5645 & Sagami Sea, Kanagawa & $681-716$ & $2007 / 11 / 28$ & Non type & AB605109 & Okanishi \& Fujita, 2013 \\
\hline 23 & Astrothorax misakiensis & NSMT E-6266 & Off Toshima Isl., Tokyo & $266-312$ & $2008 / 8 / 6$ & Non type & AB605116 & Okanishi \& Fujita, 2013 \\
\hline
\end{tabular}




\section{Table 2 (on next page)}

Tabular key to the species of the Astrocladus in Japanese waters.

Tabular morphological characteristic key to Astrocladus annulatus, A. coniferus, A. dofleini and $A$. exiguus in Japanese waters. 
1 Table 2. Tabular key to the species of the Astrocladus in Japanese waters.

\begin{tabular}{|c|c|c|c|c|}
\hline & $\begin{array}{c}\text { Shape of external ossicles } \\
\text { on dorsal disc }\end{array}$ & Shape of tubercles on dorsal disc & $\begin{array}{l}\text { Position of tubercles } \\
\text { on dorsal disc }\end{array}$ & $\begin{array}{c}\text { Hooklet-bearing plates } \\
\text { on proximal arm }\end{array}$ \\
\hline $\begin{array}{c}\text { A. annulatus } \\
\text { Matsumoto, } 1911\end{array}$ & Granule-shaped & Domed & On radial shield & Continuous \\
\hline $\begin{array}{l}\text { A. coniferus } \\
\text { (Döderlein, 1910) }\end{array}$ & $\begin{array}{l}\text { Conical on the peripheral part } \\
\text { Granule-shaped on other parts }\end{array}$ & Conical & At periphery edge of radial shield & Discontinuous \\
\hline $\begin{array}{l}\text { A. dofleini } \\
\text { Döderlein, } 1910\end{array}$ & Granule-shaped & Domed & Scattered on whole dorsal disc & Absent \\
\hline $\begin{array}{c}\text { A. exiguus } \\
\text { Lamarck, } 1816\end{array}$ & Conical with acute thorny tip & Conical & Scattered on whole dorsal disc & Discontinuous \\
\hline
\end{tabular}

2 